Surveys in Geophysics manuscript No.

(will be inserted by the editor)

\title{
The 3D attenuation structure of Deception Island (Antarctica)
}

\author{
J. Prudencio · L. De Siena · J. \\ M. Ibáñez • E. Del Pezzo • A. \\ García-Yeguas · A. Díaz-Moreno
}

Received: date / Accepted: date

\footnotetext{
J. Prudencio

Instituto Andaluz de Geofísica, University of Granada, Profesor Clavera 12, 18071 Granada, Spain

Dept. Fisica Teórica y del Cosmos, University of Granada, Fuentenueva S/N, 18001 Granada, Spain

INVOLCAN, Antiguo Hotel Taoro, Parque Taoro 22, 38400 Puerto de la Cruz, Tenerife, Spain

E-mail: janire@ugr.es

L. De Siena

University of Münster, Institut für Geophysik, Correnstrasse 24, Münster, 48149, Germany.

University of Aberdeen, School of Geosciences, Geology and Petroleum Geology, Meston

Building, King's College, Aberdeen AB24 3UE Scotland

Tel. +492518334725

Fax +492518336100

E-mail: lucadesiena@uni-muenster.de

J. M. Ibáñez

Instituto Andaluz de Geofísica, University of Granada, Profesor Clavera 12, 18071 Granada, Spain

Dept. Fisica Teórica y del Cosmos, University of Granada, Fuentenueva S/N, 18001 Granada, Spain

Istituto Nazionale di Geofisica e Vulcanologia, Sezione di Catania -Osservatorio Etneo, 95125

Catania, Italy

E. Del Pezzo

Istituto Nazionale di Geofisica e Vulcanologia, Sezione di Napoli -Osservatorio Vesuviano, Via Diocleziano 328, 80124 Naples, Italy

Instituto Andaluz de Geofísica, University of Granada, Profesor Clavera 12, 18071 Granada, Spain

A. García-Yeguas

Dept. Física Aplicada, University of Cádiz, Av. Duque de Nájera 18, 11002, Cádiz, Spain

Instituto Andaluz de Geofísica, University of Granada, Profesor Clavera 12, 18071 Granada, Spain

INVOLCAN, Antiguo Hotel Taoro, Parque Taoro 22, 38400 Puerto de la Cruz, Tenerife, Spain
} 
Abstract The seismic and volcanological structure of Deception Island (Antarctica) is an intense focus topic in Volcano Geophysics. The interpretations given by scientists on the origin, nature, and location of the structures buried under the island strongly diverge. We present a high-resolution 3D $P$-wave attenuation tomography model obtained by using the coda normalization method on 20.293 high-quality waveforms produced by active sources. The checkerboard and synthetic anomaly tests guarantee the reproduction of the input anomalies under the island down to a depth of $4 \mathrm{~km}$. The results, once compared with our current knowledge on the geological, geochemical, and geophysical structure of the region, depict Deception as apiecemeal caldera structure leant out of the Bransfield Trough. High attenuation anomalies contouring the north-eastern emerged caldera rim correlate with the locations of sediments. In our interpretation, the main attenuation contrast, which appears under the collapsed southeastern caldera rim, is related to the deeper feeding systems. A unique $P$-wave high attenuation spherical-like anomaly in the inner bay extends between depths of 1 and $3 \mathrm{~km}$. The northern contour of the anomaly coincides with the calderic rim both at 1 and $2 \mathrm{~km}$, while smaller anomalies connect it with deeper structures below $3 \mathrm{~km}$, dipping towards the Bransfield Trough. In our interpretation, the large upper anomaly is caused by a high-temperature shallow (1 to $3 \mathrm{~km}$ deep) geothermal system, located beneath the sedimentfilled bay in the collapsed blocks and heated by smaller, deeper contributions of molten materials (magma) rising from southeast.

Keywords Attenuation S Scattering · Tomography · Antarctica

\section{Introduction}

Deception Island (Fig. 1) is considered as a laboratory for Volcano Geophysics due to the large number of multidisciplinary studies focused both on imaging its surface and deep structures and on monitoring its volcanic activity. Scientists have widely studied the origin and morphology of Deception Island, bringing formed general and local models (e.g. Martí et al 1996, 2013; Smellie et al 2002; Fernández-Ibáñez et al 2005; Maestro et al 2007; Barclay et al 2009; Melo et al 2012; Torrecillas et al 2012, 2013). The study of the seismic activity of the volcano is probably the most active and productive research line, as reported by Tejedo et al (2014). There are many results that help to better understand the dynamic and volcanological framework of the area as Vila et al (1992), Almendros et al (1997), Ibáñez et al (1997), Ibáñez et al (2000), Ibáñez et al (2003), Saccorotti et al (2001), Martinez-Arevalo et al

A. Díaz-Moreno

Instituto Andaluz de Geofísica, University of Granada, Profesor Clavera 12, 18071 Granada, Spain

Dept. Fisica Teórica y del Cosmos, University of Granada, Fuentenueva S/N, 18001 Granada, Spain

INVOLCAN, Antiguo Hotel Taoro, Parque Taoro 22, 38400 Puerto de la Cruz, Tenerife, Spain 
(2003), Benitez et al (2007), Carmona et al (2010), Carmona et al (2012), Carmona et al (2014) and García-Yeguas et al (2010). One of the objetives of these seismic studies is to provide 2- or 3-D structure of the area, by using active or passive data as has been done by (Ben-Zvi et al 2009; Zandomeneghi et al 2009; Prudencio et al 2013). These seismic models have been used to confirm or help to built other geophysical or geodinamic models of the island, as magnetotelluric (Pedrera et al 2012), geomagnetic (Muñoz Martín et al 2005), gravimetric (Catalan et al 2006) or geodetic (Berrocoso et al 2012; Prates et al 2013). Aditionally, geochemical analysis as the composition and ratio of stable isotopes and gasses produced by fumaroles (Caselli et al 2004, 2007; Kusakabe et al 2009) are also very well know, and provide important information on the presence and origin of magma and fluids. Nowadays with these observables the research community is working to provide a geodinamic and volcanological model that could unify all of them in a single interpretation as those done by (Smellie 2001; Martí et al 2013; Berrocoso et al 2012; Pedrera et al 2012).

The imaging of region-specific velocity and attenuation through directwave tomography provides striking results at local, regional, and global scales (e.g. Schurr et al 2003 and Eberhart-Phillips et al 2008). Attenuation tomography is today a standard technique and several codes include this important measurement in their tomographic algorithms (Lees and Lindley 1994; Schurr et al 2003; Hansen et al 2004; Eberhart-Phillips et al 2008; Koulakov et al 2010). Due to the higher sensitivity of the attenuation parameters to the presence of fluids and melt with respect to velocity, attenuation tomography may provide decisive data to discriminate the location and nature of the volcanic and seismic structures under Deception Island.

The modeling of energy (amplitude) propagation in highly-heterogeneous local-scale volcanic media is especially complicated by frequency-dependent source and site effects. In these media, scattering phenomena produce highfrequency long wave-trains of incoherent radiation (coda waves, e.g., Sato et al 2012), affected by dispersion as well as by interference, diffraction, and resonant effects. The coherency in the corresponding direct signals is also quickly lost (La Rocca et al 2001; Chouet 2003; De Siena et al 2013). In these media, we may retrieve $P$ - and $S$-wave attenuation parameters independently of the site and instrumental transfer functions by using the coda-normalization method (Aki and Richards 1980; Yoshimoto et al 1993; Sato et al 2012). In recent years, this method has been applied to $S$-wave attenuation tomography at local scale, exploiting the strong scattering effects produced by strong heterogeneity in volcanic regions (Del Pezzo et al 2006; Matsumoto et al 2009; Sato et al 2012; De Siena et al 2010).

The coda-normalization method is based on the equation that correlates the ratio between the S-wave direct energy and the coda-wave energy to the spatial distribution of the inverse total quality factors calculated along the source-station ray-path (Del Pezzo et al 2006; De Siena et al 2009, 2014). If active sources are available, the spatial distribution of $P$-wave attenuation becomes the only unknown if the final coda-normalization inverse problem, that is, the method may be exploited at best. 
In this study, we obtain the $P$-wave total quality factor $\left(Q_{p}\right)$, which measures the anelastic and scattering losses suffered by $P$-waves while propagating into the medium. This quantity provides information on the physical, chemical, and geological state of the Earth, and becomes especially useful if compared with seismic velocities. A wide range of physical properties must be considered before discussing the joint results of velocity and attenuation tomography. Their combined interpretation is a decisive tool in discriminating volumes either permeated by fluids or characterized by structural discontinuities (Schurr et al 2003; Eberhart-Phillips et al 2008; De Siena et al 2010).

The relation between velocity and attenuation is often ambiguous. High attenuation and low velocity do not always mean the presence of melt in volcanoes, as fluids, gasses, faults, and, more generally, unconsolidated materials (like sediments) all produce high attenuation in the presence of different velocity signatures (Haberland and Rietbrock 2001; Schurr et al 2003; Hansen et al 2004; De Siena et al 2010; Muksin et al 2013). Several authors (e.g., Priyono et al 2011) suggest that high $\triangle Q_{p}^{-1}$ and low $\Delta V_{p}^{-1}$ in volcanic regions are related to a magmatic system, while others (e.g., Takanami et al 2000) relate these correlation to high-temperature zones without partial melting.

The $P$-to- $S$ velocity ratio $\left(V_{p} / V_{s}\right)$ is a decisive parameter to discriminate magma from either fluids or gasses if spatially correlated with high attenuation (Hansen et al 2004; Vanorio et al 2005; De Siena et al 2010; Kuznetsov and Koulakov 2014). Low $V_{p} / V_{s}$ anomalies and high attenuation may in fact be associated with the presence of gas filling faults and fractures, hydrothermal basins, and $\mathrm{CO}_{2}$ emission beneath volcanoes, mountain ranges, and geothermal reservoirs (Julian et al 1996, 1998; Hunsen et al 2004; Hansen et al 2004). The correlation of high $V_{p} / V_{s}$ with high attenuation is critical to discriminate fluids from melt. As no $V_{p} / V_{s}$ ratio information is available at Deception Island other geophysical, geological, and geochemical information must be considered with care in the final interpretation.

The aim of this study is to obtain reliable 3D frequency-dependent $P$ wave attenuation images of the upper $4 \mathrm{~km}$ beneath Deception Island (South Shetland archipelago, Antarctica) by using a subset of the waveforms employed by Ben-Zvi et al (2009) and Zandomeneghi et al (2009) to obtain velocity tomography results. We will provide new evidences that can be used in the future in a new geophysical interpretation by the comparison of the velocity and attenuation results with the current and new scientific results focused on the formation and structure of the Island.

\section{Deception Island: volcanological and geophysical models}

Deception Island is an active volcanic island composed by rocks that date to less than 0.75 Ma and which suffered several historical eruptions in the last two centuries (Smellie 2001) (Fig. 1) . Nowadays its volcanic activity mainly consists of hot hydrothermal waters, fumarolic fields and intense seismic activity composed by volcanic tremor, persistent long-period and volcano-tectonic 
seismicity (Vila et al 1992; Ortiz et al 1997; Ibáñez et al 2000; Carmona et al 2012).

As indicated above, many of the present efforts of several researchers are focused in the interpretation of the geophysical, geodetic and geochemical observations in terms of structural and volcanological framework of the volcano to understand its past and to infer a possible evolution and volcanic dynamic. These researchers integrated seismic observations, mainly low and high seismic velocities and contrast in attenuation, conductivity, gases and geodetical information. On the base of these observations there are mainly at the present two possible models that are coincident in the interpretation of the shallower structure $(0-2 \mathrm{~km})$ and they are in desagree in the interpretation of the deeper structure. In one of them the effects of fractured rocks and the existence of a geothermal system that hydrothermally altered the medium is detected up to $6 \mathrm{~km}$ depth (Martí et al 2013). In the other, the observed anomalies are interpreted as the effects of the presence of certain amount of melted rock/material with variable volume (e.g. Ben-Zvi et al 2009; Pedrera et al 2012; Muñoz Martín et al 2005).

\subsection{Deep Geothermal effect}

Recently, Martí et al (2013) on the base of new stratigraphy and petrological studies, with the revision of previous results proposed a model of the formation and internal structure of the Island. In reference to the present internal structure, the authors show that a polygonal structural network consisting of several pre-existing major normal faults controlled pre- and post- caldera volcanism on the island. They defend that the formation of the caldera caused the destruction of the associated magma chamber and hence, recent eruptions have been fed by small batches of deeper-source magma. In their interpretation, a large hydrothermal system developed in the interior of the depression using highly fractured pre-caldera basement and syn-caldera rocks. The authors suggested that the current hydrothermal system inside its depression, which may be responsible for most of the present-day observations up to $6 \mathrm{~km}$ depth.

\subsection{Existence of melted material}

Mostly of the geophysical and geodetic studies performed in the area observed the existence of high constrast of the physical properties studied and these anomalies have an evident presence in the central part of the island (bellow Port Foster). These anomalies extend up to 6-10 km depth and their interpretations include the existence of partial melted rocks at depths $2-10 \mathrm{~km}$.

Seismic velocity observations: Ben-Zvi et al (2009) and Zandomeneghi et al (2009) used the data-set provided by the TOMODEC active seismic experiment to obtain $2 \mathrm{D}$ and $3 \mathrm{D}$ images of $\mathrm{P}$-wave velocity structure in the 
entire area of Deception Island between depth of 0 to $10 \mathrm{~km}$. Their results show strong deep (down to $8 \mathrm{~km}$ ) lateral velocity variations, which are attributed to the presence of crustal magmatic systems with either partial melt regions and frozen intrusive bodies or sediment thickness variations and geothermal systems. The authors indentified a large high-velocity anomaly intersects the northwestern part of Deception Island (Telefon Bay, Fig. 1) taht was associated with the crystalline basement of the South Shetland Island platform. However, the main feature of the velocity models is an extended low $\mathrm{P}$-wave velocity anomaly, which intersects both Port Foster bay and eastern part of the island (Fig. 1). The same authors interpret the shallow how velocity anomalies (0-2 $\mathrm{km}$ ) as the effect of sediment-filled basin, hydrothermal activities, fractured materials from the caldera collapse and others. Ben-Zvi et al (2009) (pp.78) on the base of numerical simulations observed that the velocity anomalies bellow $2 \mathrm{~km}$ depths are compatible with the presence of partial melted materials (up to $15 \%$ melted) and with a maximum volume of up $20 \mathrm{~km}^{3}$. Zandomeneghi et al (2009) agree this interpretation.

Seismic attenuation observations: Regarding seismic attenuation, Vila et al (1995) obtained local attenuation parameters from both coda analysis and source parameters information. The authors show abnormally low coda-Q values characterized by high frequency dependence in the inner bay of the island. They do interpret it as due to a hot magmatic intrusion produced during the most recent eruption, but the width of this intrusion is estimated to be only about $0.2 \mathrm{~km} 3$. More recently Martinez-Arevalo et al (2003) estimated the seismic attenuation of both P- and S-waves at Deception Island, observing a predominance of scattering- over intrinsic- attenuation. They do interpret these results as produced by a zone of strong heterogeneity, as done in most volcanic areas (Del Pezzo 2008), where the presence of magma patches cannot be excluded. Recently, Prudencio et al (2013) obtained the regional 2D distribution of intrinsic and scattering attenuation of the Island by using the same waveform dataset employed to image its velocity structure and the diffusion model. The authors confirm the presence of a high scattering attenuation body below the inner bay of Deception Island, strongly interacting with the coda wave-field, and which may be compatible with the existance of magma.

Gravimetric and magnetotelluric observations: Muñoz Martín et al (2005) show a very low density anomaly in both magnetic and gravity anomaly maps of Deception Island. The authors interpreted this anomaly as a partially melted intrusive body and they estimated the top of this body at $1.7 \mathrm{~km}$ depth using Euler deconvolution techniques. The 3D resistivity models of Pedrera et al (2012) reveal an elongate conductor between 2 and $10 \mathrm{~km}$ east of Whalers Bay (Fig. 1), which they interpret as induced by a combination of partial melt and hot fluids. The inferred deep magma sill is connected to the surface by a large resistive path ending Port Foster, interpreted as a shallow magma chamber. 


\section{Data, method, and inversion setting}

3.1 Data and ray tracing.

The waveforms used in this study are a subset of the ones used by Zandomeneghi et al (2009) to obtain 3D velocity images by using a shortest-time ray tracing and a LSQR algorithm inversion. The authors choose two different model parametrizations. The first grid has coarser parametrization $(250 \mathrm{~m})$, it is centered on Deception Island and extends $53 \mathrm{~km}$ from West to East (WE), $52 \mathrm{~km}$ from South to North (SN), and down to $12 \mathrm{~km}$ depth. A smaller grid of $100 \mathrm{~m}$ step includes Port Foster and the nearest surroundings, and extends 12 $\mathrm{km}$ WE, $14 \mathrm{~km} \mathrm{SN}$, and down to $7 \mathrm{~km}$ depth. In order to compare the velocity and attenuation models we use a grid having the same lateral extension of the first grid in Zandomeneghi et al (2009).

Amplitude data are strongly frequency dependent. We show four recordings produced by a shot in the center of the bay (blue star) and registered at stations M, F, J, and H (Fig. 2). The stations record waveforms with excellent signal-to-noise ratios (larger than 10) for the entire signal above $8 \mathrm{~Hz}$ only. However, both Vila et al (1995) and Prudencio et al (2013) show abnormallylow attenuation values at high frequencies in the Port Foster bay, where we focus our attention. Due to this strong attenuation we cannot provide reliable attenuation models of structures as deep as $4 \mathrm{~km}$ at frequencies larger than $10 \mathrm{~Hz}$.

We obtain the attenuation model after filtering data in the 4-8 frequency band ( $6 \mathrm{~Hz}$, central frequency). Considering the lowest measured velocities in the inner bay, the signal wavelenght associated with this frequency band safely allows to depict structures of the order of $1 \mathrm{~km}$ dimension at $4 \mathrm{~km}$ depth. As shown by Prudencio et al (2013) this frequency band also provides stable results for the separate measurements of both intrinsic and scattering attenuation from coda wave data.

We use the same Thurber-modified ray-bending approach described, e.g., by De Siena et al (2010) in the 3D sparse velocity model of Zandomeneghi et al (2009) (Fig. 3). The space density of the rays at depth of $5 \mathrm{~km}$ is still sufficient for correctly performing the tomography inversion (Figure 3). On the other hand, observational data associated with these paths show highly incoherent estimates even for paths crossing almost the same volumes. Therefore, our analysis and final interpretation is restricted to depths of 1 to $4 \mathrm{~km}$ : these analysis may provide hint on deeper structures once compared with other measurements.

\section{$3.2 P$-wave attenuation tomography with the coda normalization method}

The coda-normalization (CN) method has been first applied to the singlestation estimate of the total S-wave inverse quality factor $Q$ along the seismic path by Del Pezzo et al (2006) in the Mount Vesuvius volcanic area. The 
single-path attenuation is obtained in a given frequency range with central frequency $f_{c}$ by measuring the direct-S energy $\left(E_{k}^{s}\right)$ and the coda-S energy in a time window centered around a given lapse time $t_{c}\left(E_{k}^{c}\left(f_{c}, t_{c}\right)\right)$, and calculating their ratio. The single-path $\mathrm{CN}$ equation is:

$$
\frac{1}{\pi f_{c}} \ln \left(\frac{E_{k}^{s}\left(f_{c}\right)}{E_{k}^{c}\left(f_{c}, t_{c}\right)}\right)=K\left(f_{c}, t_{c}, \theta, \phi\right)-\frac{2}{\pi f_{c}} \gamma \ln \left(r_{k}\right)-2 \int_{r_{k}} \frac{d l}{v(l) Q(l)}
$$

where $r_{k}$ is the total length of the $k^{t h}$ ray, $\gamma$ is the geometrical spreading, and $v(l)$ is the velocity of the medium measured along the ray-path. $K\left(f_{c}, t_{c}, \theta, \phi\right)$ takes into account the effect of the source radiation pattern, described by the take-off angle $(\theta)$ and azimuth $(\phi)$ and is the only other unknown variable (apart for $Q$ ) in the equation. As in given frequency bands diffraction effects, waveguides, and surface waves could affect the exponent $\gamma$ of the geometrical spreading we choose to invert this parameter with the inverse average quality factor (La Rocca et al 2001; Morozov 2011; De Siena et al 2014).

As shown by Yoshimoto et al (1993) we can extend the CN method to the measurement of $P$-wave average attenuation (the $P$-wave quality factor, $Q_{p}$ ). We use active sources, that is, only $P$-waves are produced. We can reasonably assume a spherical source radiation pattern, hence, $K\left(f_{c}, t_{c}, \theta, \phi\right)=K\left(f_{c}, t_{c}\right)$, leaving $Q_{p}$ as the only unknown in the inversion problem. We can thus apply the $\mathrm{CN}$ method to $P$-wave attenuation tomography under three assumptions:

- the small $P$ - and $S$-wave mean free paths in the volcanic structures allow for a quick conversion of $P$-wave energy into coda energy,

- the seismic paths traveled by the waves producing the energy ratios filtered in the chosen frequency band can be approximated by a ray (curve),

- the lapse-time from origin is large enough to measure coda energy out of the $P$-wave transient regime.

The energy ratios vs. travel times behaviour reveal no evident anomalous energy-ratio increase localized in space at $6 \mathrm{~Hz}$, indicative of anomalous coherent effects in the coda envelopes (De Siena et al 2014). As the lapse time $t_{c}$ strongly influences the estimates of the average parameter if it is set to short lapse-times (Calvet and Margerin 2013) we set the start of the coda time-window of length $3 \mathrm{~s}$ to a lapse-time of $12 \mathrm{~s}$. The $P$-energy time window is set to $1.5 \mathrm{~s}$. The waveforms were selected depending on the coda-to-noise ratio (always larger than 1.5 ) at $6 \mathrm{~Hz}$.

The final data-set is comprised of 20293 vertical seismic waveforms. The inversion of the energy ratios for the average parameters provides an average $Q_{p}$ of 29: in the following we will discuss the variations with respect to the inverse of the average quality factor in the $3 \mathrm{D}$ space $\left(\Delta Q_{p}^{-1}\right)$, a direct measurement of attenuation. By considering these observations as well as the ideal distribution of our sources we invert the energy ratios for the attenuation parameters with the MuRAT code in a single-step inversion (De Siena et al 2014). 


\section{Synthetic tests}

We want to discriminate the resolution we effectively achieve on a high attenuation anomaly in the center of the bay down to $4 \mathrm{~km}$ depth (Fig. 4). We start testing the resolution of the $\Delta Q_{p}^{-1}$ results assuming as input synthetic anomaly a high attenuation region in the centre of the island, roughly designed on the results of the velocity tomography (Figure 4, high attenuation correlated with high velocity). Hence, we impose a $8 \times 8 \times 4 \mathrm{~km}^{3}$ volume of low quality factor under Port Foster. We generate synthetic $P$-to-coda energy ratios and we add Gaussian random error with zero mean and 3 times the standard deviation, equal to the $20 \%$ of the data value. We invert the synthetic data only in blocks crossed by at least 5 rays. We show the results on four horizontal slides at different depths (Fig. 4).

In order to test the resolution in the entire region we also perform a checkerboard test, whose output is shown on the same 4 horizontal slices used in Fig. 4 (Fig. 5, third column). We add the same amount of Gaussian random error to the synthetic $P$-to-coda energy ratios calculated from a checkerboard synthetic structure with $2 \mathrm{~km}$ node spacing, starting at $0 \mathrm{~km}$, and having quality factors equals either to 100 or 1000 . The checkerboard and synthetic anomaly test inputs and outputs are also shown on SN and WE vertical sections, crossing the inner bay (Fig. 3, dotted gray line).

The checkerboard test results are well resolved everywhere between depths of 1 and $3 \mathrm{~km}$, while smearing affects the output at $4 \mathrm{~km}$ depth, especially in the regions contouring the island (Fig.s 5). The synthetic anomaly test is well resolved down to $4 \mathrm{~km}$ depth except for some smoothing on the southern and western sides of the images, between depths of 1 to $3 \mathrm{~km}$ (Fig.s 4 and 6). We conclude that we have good resolution in the volume under study. Also, a high attenuation anomaly, located in the center of the bay and as deep as 4 $\mathrm{km}$, can be obtained by the inversion of real data.

\section{Results and joint interpretation with the geological and geophysical results.}

Fig. 5 shows 4 horizontal slices through the velocity and attenuation models down to a depth of $4 \mathrm{~km}$ (left-hand and central columns). Fig. 6b,c shows two vertical sections of these models, following the WE and SN directions as shown in Fig. 3 (gray dotted line). The $P$-wave percent velocity variations $\left(\% \Delta V_{p}\right)$ are calculated by the $P$-wave velocity model of Zandomeneghi et al (2009). The interpretation of our results is based on the analysis of the largest attenuation anomalies in the regions of major volcanological interest (Fig. 7).

In order to correlate the velocity and attenuation anomalies with those obtained by other geophysical and geological studies we discuss the results under the Oceanic Crust and caldera structure separately from the ones under the Port Foster. We also separate the discussion of the anomalies under Port 
Foster bay in two different depth ranges (between depths of 1 and $2 \mathrm{~km}$ and between depths of 3 and $4 \mathrm{~km}$ ).

\subsection{Oceanic Crust and caldera structure}

No unique high-attenuation anomaly larger than $2 \mathrm{~km}$ is visible under the Oceanic Crust contouring the island. An arc-shaped volume of small $(2 \mathrm{~km}$ average dimension) high-attenuation anomalies is located northeast of Deception at a depth of $1 \mathrm{~km}$ (Fig. 5). This volume, located in a low-velocity zone, is partially visible in the $2 \mathrm{~km}$ tomograms. (Zandomeneghi et al 2009) interpret the vast superficial low-velocity anomaly northeast of the island (1 to $2 \mathrm{~km}$ depth, Fig. 5, left-hand column) as a zone of accumulation for sedimentary materials and hydrothermal activity. From the depth extension and location of the high-attenuation arc-shaped volume we confirm this interpretation, in the sense that the high attenuation anomaly may actually locate the inner boundary of the sedimentary structures and hydrothermal interactions.

Most of the source energy recorded near this boundary crosses the Port Foster bay, that is, the most attenuating structure in the entire region (Vila et al 1995; Martinez-Arevalo et al 2003). The fractured caldera as well as the faults contouring the inner bay may also reflect or diffract direct energy. Hence, we may not expect to image the exact lateral extension of these sediments: we may safely assume that velocity tomography provides more reliable information on these structures.

Under the south-south-eastern part of the caldera structure, which constitutes the part of Deception emerged out of the Ocean, we observe the largest attenuation contrast, marking the entire depth range (e.g., Fig.s 6c and 7 SN). The low attenuation visible under the caldera defines an almost vertical boundary with the high attenuation medium under Port Foster, in strong correlation with the location of deep normal faults. The southern part of Deception is also affected by large smearing (Fig. 6d), induced by the large velocity contrast affecting the deep geometry of each source-station ray passing through it.

Pedrera et al (2012) obtain a vast conductive body extending SE of the Island between depths of 2 and $12 \mathrm{~km}$. The authors suggest emplacement of melt in this volume driven by an ENE-WSW oriented and SSE dipping regional normal fault. An almost vertical low-velocity and high-resistivity anomaly between depths of 2 and $6 \mathrm{~km}$ is located below Port Foster, connecting the vast southeastern high-resistivity anomaly with the center of the island. The vertical attenuation contrast is laterally disposed above the northwestern limit of the deep high resistivity anomaly (Fig. 7).

Our results are compatible with previous studies (Ben-Zvi et al 2009; Zandomeneghi et al 2009; Pedrera et al 2012) affirming that the south-southeastern part of the Island may contain a certain volume of a fluid/melt which may be the feeding path for the caldera. The section of this path, which should be connected to the center of the island and present high attenuation, reduces to our node spacing in the attenuation images at $4 \mathrm{~km}$ depth (Fig. 5, 4km). 
Additionally, our results are also compatible with other interpretation provided by Martí et al (2013) in which the deep feeding structures may simply heat the upper crustal systems, where meteoric waters both penetrate and circulate producing the high-attenuation anomaly in the centre of the caldera (Fig. 7).

Deception faces the Bransfield Through from northwest (Martí et al 2013). The collapsed part of its caldera structure corresponds to the northwestern margin of the Through as well as to both steep almost-vertical normal faults and strong attenuation contrasts (Fig. 7, upper-right panel). Velocity and resistivity tomograms show clear low-velocity and high-resistivity connections of the upper anomalies with deeper vast high-resistivity regions, extending southeast of the island (Fig. 7, vertical section). Our results are in concordance with those obtained by Pedrera et al (2012) which suggested that the feeding system, through which fluids and melt materials either pass or heat the upper crustal materials, starts south-east of the Island at around $6 \mathrm{~km}$. The main connection with the surface rises almost vertically towards the southeastern margin of the Island (Zandomeneghi et al 2009; Pedrera et al 2012), passing through the high-attenuation contrasts southeast of the Island (Fig. 7). We discuss in the next two sections if, how, and where the deep melt materials are stored in the first $4 \mathrm{~km}$ under Deception.

\subsection{From depths of 1 to $2 \mathrm{~km}$ under Port Foster}

The Port Foster Bay (inner bay of Deception Island, Fig. 1) is dominated by a large $\triangle Q_{p}^{-1}$ positive anomaly, that is, by high attenuation, down to a depth of $2 \mathrm{~km}$ (Fig. 5, central column, red). In this depth range the high-attenuation volume is contoured by average-to-low attenuation structures, mainly corresponding to the exposed caldera rim (Figs. 5 and $6 \mathrm{c}$ ). Zandomeneghi et al (2009) and Luzón et al (2011) both propose that unconsolidated volcanoclastic and volcano-sedimentary materials, possibly producing high attenuation, extend down to $1.2-1.4 \mathrm{~km}$ depth. We remark, that the anomaly in the centre of the bay shows much higher attenuation than the surroundings. This is particularly relevant if we compare the results in the central bay with the arc of high attenuation located northeast of the island, where low velocities are also interpreted as induced by sediments (Zandomeneghi et al 2009).

The strong $P$-wave attenuation is paired with a strong scattering signature (obtained by Prudencio et al (2013) under the bay) and suggests that materials with higher attenuation capacity than sediments, like hydorthermal interations, intrude the first $2 \mathrm{~km}$ depth under the Port Foster bay. The top of a resistivity anomaly obtained by Pedrera et al (2012) resembles pretty well the low velocity and high attenuation structure under the bay at a depth of 2 km (Fig. 5, see also Zandomeneghi et al (2009)).

Getting S-wave velocity information is important for the interpretation of the attenuation anomalies. Luzón et al (2011) provide us information on the transverse velocity wave-field between depths of 1 and $2 \mathrm{~km}$. The lowest 
S-wave velocities (related in the interpretation of Luzón et al (2011) to the alterations produced by hydrothermal activity) are near Chilean station (Fig. 1) northeast of the bay. On the contrary, the largest velocities occur near the SW caldera border, revealing the presence of compact materials at shallow depths. The low velocity anomaly obtained by Luzón et al (2011) at $1 \mathrm{~km}$ matches with the high-attenuation unique anomaly shifted towards the north part of the bay.

De Siena et al (2010) depict zones of fluid accumulation coupled to a surrounding network of normal faults beneath Pozzuoli (Campi Flegrei, Italy), where the correlation of high attenuation and high $V_{p} / V_{s}$ anomalies (Vanorio et al 2005) is striking. This high attenuation anomaly is contoured by a hard rock volume and associated with the caldera rim structure: this image is very similar to the one we observe at Deception (compare our results with De Siena et al (2010), Fig. 7c, markers X4, X5, and X6). In De Siena et al (2010) the presence of melt is restricted to a small volume located at a depth of about $4 \mathrm{~km}$ embedded in a hard rock volume, and heating the geothermal system under Pozzuoli.

The lateral extension of the high attenuation anomaly at Deception is actually coincident with the bathymetry of the floor of the bay (Fig. 6a), which reveals a broad uplift of the eastern side of the caldera (Cooper et al 1999). As proposed by Barclay et al (2009) bathymetric results could be caused by sediment supply rates and hydrothermal alterations from the east of the island or by a trap-door caldera deformation with its minimum subsidence in the east. Both these causes are compatible with permeation of local meteoric water and seawater in the intra-caldera formation.

Other additional evidences of the nature of sediment deposits, volcanoclastic materials and hidrothermal alteration effects on the first $2 \mathrm{~km}$ shallow part of the caldera floor, is obtained by the study of some geochemical aspects of the area as the study of isotopes and noble gas data from fumarolic and bubbling gases and hot spring waters (Kusakabe et al 2009). $\mathrm{He}$ and $\mathrm{CO}_{2}$ are mainly of mantle origin, with no contribution of magmatic water to water and gas samples, hot spring fluids being a mixture of local meteoric water and seawater. Kusakabe et al (2009) infer that these results are due to the existence of a heated hydrothermal system, with different temperatures in the depth range between 1 and $2 \mathrm{~km}$.

The shape of the high attenuation anomaly, contoured by the low-attenuation caldera rim between depths of 1 and $2 \mathrm{~km}$ (Fig.s 5 and 6) is similar to the one retrieved under different calderas and associated with the presence of hydrothermal alteration. The large low-velocity and high-attenuation structure in the bay (Fig.s 5 and $6 \mathrm{~b}, \mathrm{c}$ ) correlates well with high resistivity, high scattering attenuation, and low S-wave velocities. Therefore, attenuation anomaly shows a portion of the collapsed caldera center permeated by a geothermal reservoirs, at least between depths of 1 and $2 \mathrm{~km}$. 


\subsection{From depths of 3 to $4 \mathrm{~km}$ under Port Foster}

Low velocity and high attenuation anomalies are less strong at depths larger than $2 \mathrm{~km}$ under Port Foster (Fig.s 5 and 6 ). The percent velocity variations show a continuous vertical anomaly between depths of 3 and $4 \mathrm{~km}$, while the high-attenuation anomaly is shaped as a spherical-like system having its basis approximately at $3 \mathrm{~km}$ depth (Fig. 6b,c). No large unique high-attenuation anomaly is visible at a depth of $4 \mathrm{~km}$ in the centre of the bay (Fig.s 5 and $6 c)$. High-attenuation anomalies with lateral extensions of the order of our node spacing connect the upper high attenuation semi-spherical anomaly with depth. Our assumption is that seismic attenuation is more sensitive to the presence of deep melt and fluids than seismic velocity, while velocity tomography is able to sample larger depths (Hansen et al 2004; De Siena et al 2010; Muksin et al 2013).

In their 2D and 3D resistivity maps Pedrera et al (2012) also reveal an ENE-WSW elongated conductor located between 2 and $6 \mathrm{~km}$ depth beneath the Port Foster bay, which they interpret as induced by a combination of partial melt and hot fluids. The depth resolution of the magnetotelluric model, which defines quite precisely the top of melt/fluid regions, is affected by the resistivity of the superficial highly-resistive marine layers. This may cause an incorrect depth definition of the highly resistive structures. As in attenuation tomography we use ray-dependent measurements we assume we provide higher resolution than in magnetotelluric imaging, again at the expense of depth sampling.

The attenuation tomograms clearly show that the anomaly extends down to a maximum depth of $3 \mathrm{~km}$ as a unique hemispherical body. The depth extension and shape of the high attenuation anomaly at depths of 3 to $4 \mathrm{~km}$ is similar to the ones observed in other areas, e.g., by De Siena et al (2010) in the Campi Flegrei caldera, by Muksin et al (2013) in the Tarutung Basin, and by Bohm et al (2013) in the Kendeng Basin. These observations are always related to sedimentary or volcanoclastic deposits overlying active geothermal and gas reservoirs.However, other studies, interpret this high attenuation anomaly and low velocity body as the presence of shallow partial melted magma body such as Koulakov et al (2009) and Jaxybulatov et al (2014) in Toba caldera or Ohlendorf et al (2014) in Okmok Volcano. In Okmok volcano the authors found the same patterm of velocity and attenuation observed in Deception Island and they interpreted the shallow part of the anomaly (surface to $2 \mathrm{~km}$ ) as caldera fill, groundwater and small pods of magma and the deeper part of the anomaly (from 4 to $6 \mathrm{~km}$ ) as a magma storage zone. This geodynamic model is compatible with the subduction processes or slab rollback suggested by Maestro et al (2007).

As indicated previously in section 2 and above, our results are compatible with both proposed models. The modelled volume of melted rocks of Ben-Zvi et al (2009) (less than $15-20 \mathrm{~km}^{3}$ ) in depht can coexist with other effects as a network of magma and fluid filled batches of size either lower than or equal to our resolution seems the more reliable explanation for the absence 
of a unique high attenuation anomaly down to $4 \mathrm{~km}$. This network could be visible as a unique velocity and conductive anomaly, which may provide the main heat source that sustains the geothermal system in the first $3 \mathrm{~km}$ of the crust (Martí et al 2013).

\section{Conclusions}

In the present work we obtain the 3D P-wave attenuation model of Deception Island by using coda normalization method. The methodology used in this study is stable, robust and reliable. The reliability of the method is based on the similarity of results with other studies. The study of S-waves and Vp/Vs distribution might better constrain the inner structure of the island.

We have provided new results showing the complex atenuative structure of the island with the presence of bodies of low and high attenuation. As in the velocity tomography, we find a limitation in the range of depth that we are able to solve due to the structure of the thinned oceanic crust region where the Moho is 4-5 km depth and it implies a physical barrier.

One of the most important remarks is the presence of high attenuation body in the center of the island which extends from the surface to our resolution limit. The interpretation of this anomaly in the first two kilometers agrees almost all researchers who have worked on the island and is associated with the effects of sedimentary and volcanoclastic deposits, hydrothermal interactions and highly fractured material.

The interpretation of the deeper structure is more complex, mainly due to the lack of S-waves data. Thus, our results are consistent with two possible models. In the first, the high attenuation and low velocity is due to a hydrothermal system effects. On the other, this anomaly is interpreted as the existence of a partially molten magmatic body. A combination of these two models is also compatible with our results. It will be necessary to continue working to incorporate data from $\mathrm{S}$ waves or other methodologies to give light to the interpretations.

\section{Fig. captions}

Fig. 1: Regional setting and location of Deception Island in the South Shetland Islands archipelago, Antarctica (upper two panels). Bottom panel: Toponyms (bold italics), historical eruption sites (white on black rectangle), and research stations active or destroyed by the recent eruptions (regular bold), are shown on the contour map of Deception Island.

Fig. 2: The vertical records of a seismic shot produced on the 8 of January 2005 , located in the center of the Port Foster Bay (blue star), and recorded at four seismic land stations (M, F, J, H). The gray dotted line crossing near the center of the bay indicate the location and direction of the vertical sections 
shown in Fig. (6). The panels on the right show the signal spectrum (S, blue lines) and noise spectrum (N, red lines) for each recording.

Fig. 3: Configuration of the TOMODEC seismic tomography experiment. a) Land and ocean bottom seismometers (red triangles) and shots locations (gray lines) are drawn on a contour map of the island. In the top-right panel we a zoom on the center of the island (Port Foster bay). b): 3D and 2D sourcestation ray-paths obtained by using a Thurber-modified ray-bending approach. All the events are approximately located at $0 \mathrm{~km}$ depth and produced by airguns. The red contour map imposed on the rays shows the location and shape of Deception Island with respect to the experiment setting.

Fig. 4: Upper panel: The synthetic anomaly test input is designed to show the reproducibility of a simplified deep high-attenuation anomaly under the Port Foster bay. The high attenuation anomaly has a dimension of $8 \times 8 \times 4 \mathrm{~km}^{3}$ and is characterized by a quality factor of 3 . Lower panels: four horizontal slices through the output of the synthetic anomaly test taken at different depths with respect to the sea level. The $\triangle Q_{p}^{-1}$ grey scale shows the variations with respect to the average quality factor.

Fig. 5: The results of velocity tomography (Zandomeneghi et al 2009, lefthand column), of the attenuation tomography (central column) and the output of the checkerboard test (right-hand column) are shown on four horizontal slices taken at different depths. The left-hand color scale shows the percent variations of the velocity model with respect to its average. Both the central color scale and the right-hand grayscale show the variations of the attenuation model with respect to the average quality factor. The contour of Deception Island is over-imposed on each panel.

Fig. 6: Bathymetry (a), velocity model (Zandomeneghi et al 2009, b), attenuation model (c), and the synthetic tests (d) are all shown on two vertical sections crossing the Island (gray dotted lines in Fig. 3). The vertical scale in the velocity and attenuation images is enlarged for clarity. b) The color scale shows the percent variations of the velocity model with respect to its average. c) The color scale shows the variations of the attenuation model with respect to the average quality factor. d) The $\triangle Q_{p}^{-1}$ grey scale shows the variations with respect to the average quality factor. The inputs are shown above the corresponding outputs for both the checkerboard test and the synthetic anomaly test. The input of the synthetic anomaly test is described in the caption of Fig. 4.

Fig. 7: Schematic interpretation of the attenuation model, carried out with reference to the 3D velocity (Zandomeneghi et al 2009) and resistivity (Pedrera et al 2012) models, and constrained by other geophysical, geological, and geochemical observations, as described in the text. In the upper-right panel we show a horizontal section of the region taken at $8 \mathrm{~km}$ depth and depicting the portion of the Bransfield Through as well as the horizontal contour of the high resistivity anomaly contained in the region under study. We also infer from our analysis both meteoric water circulation in the upper crust and heat rising towards surface. We depict the depth dependence of the anomalies described in the text on two vertical sections, taken between depths of 0 and 
$10 \mathrm{~km}$ and crossing the Island (gray dotted lines in Fig. 3). Below a depth of $4 \mathrm{~km}$ the sketch is based on the $3 \mathrm{D}$ velocity and resistivity results only. Below $5.5 \mathrm{~km}$ the sketch is based on the resistivity model only.

Acknowledgements We gratefully acknowledge editor Dr Rycroft, Prof. Martí and one anonymous reviewer whose useful suggestions greatly improved the manuscript. This work has been partially supported by the Spanish project Ephestos, CGL2011-29499-C02-01; by the EU project EC-FP7 MEDiterranean SUpersite Volcanoes (MED-SUV); by the Basque Government researcher training program BFI09.277 and by the Regional project 'Grupo de Investigacin en Geofsica y Sismologa de la Junta de Andaluca, RNM104'. Edoardo del Pezzo has been partly supported by DPC-INGV projects UNREST, SPEED and V2 (Precursori). We also thank Christine Thomas, Ralf Hetzel, and Stephan Klemme for the important suggestions regarding both the method and the interpretation.

\section{References}

Aki K, Richards P (1980) Quantitative Seismology - Theory and Methods. W. H. Freeman, San Francisco

Almendros J, Ibez J, Alguacil G, Del Pezzo E, Ortiz R (1997) Array tracking of the volcanic tremor source at deception island, antarctica. Geophysical Research Letters 24:30693072

Barclay A, Wilcock WSD, Ibáñez J (2009) Bathymetric constraints on the tectonic and volcanic evolution of Deception Island Volcano, South Shetland Islands. Antarctic Science $21: 153-167$

Ben-Zvi T, Wilcock WSD, Barclay A, Zandomeneghi D, Ibáñez J, Almendros J (2009) The $\mathrm{P}$ wave velocity structure of Deception Island, Antarctica, from two dimensional seismic tomography. Journal of Volcanology and Geothermal Research 180:67-80

Benitez MC, Ramrez J, Segura JC, Ibez J, Almendros J, Garca-Yeguas A, Corts G (2007) Continous hmm-bases seismic-event classification at deception island, antarctica. Geoscience and Remote Sensing, IEEE Transactions 45:138-146

Berrocoso M, Prates G, Fernndez-Ros A, Garca A (2012) Normal vector analysis from gnss-gps data applied to deception volcano surface deformation. Geophysical Journal International 190:1562-1570

Bohm M, Haberland C, Asch G (2013) Imaging fluid-related subduction processes beneath Central Java (Indonesia) using seismic attenuation tomography. Tectonophysics 590:175-188

Calvet M, Margerin L (2013) Spatial variations of seismic attenuation in the Pyrenees: coda $\mathrm{Q}$ and peak delay time analysis. Bulletin of Seismological Society of America 103:doi:10.1785/0120120,239

Carmona E, Almendros J, Pea JA, báez JM (2010) Characterization of fracture systems using precise array locations of earthquake multiplets: An example at Deception Island volcano, Antarctica. Journal of Geophysical Research: Solid Earth 115

Carmona E, Almendros J, Serrano I, Stich D, Ibáñez J (2012) Results of seismic monitoring surveys of Deception Island volcano, from 1999-2011. Antarctic Science 24:485-499

Carmona E, Almendros J, Martn R, Corts G, Alguacil G, Moreno J, Martn JB, Martos A, Serrano D Ia dn Stich, Ibez J (2014) Advances in seismic monitoring at deception island volcano (antarctica) since the international polar year. Annals of Geophysics 57

Caselli A, Santos-Alfonso M, Agusto MR (2004) Gases fumarolicos de la isla Decepcion (Shetland del Sur, Antartida): Variaciones quimicas y depositos vinculados a la crisis sismica de1999. Asociación Geológica Argentina Revista 59:291-302

Caselli A, Badi G, Bonatto AL, Bengoa CL, Agusto MR, Bidone A, Ibáñez J (2007) Actividad sísmica y composición química fumarólica anómala debido a posible efecto sello en el sistema volcánico, Isla Decepción (Antártida). Revista de la Asociación Geológica Argentina 62:545-552 
Catalan M, Agudo LM, Muoz-Martin A (2006) Geomagnetic secular variations of Bransfield Strait (Western Antarctica) from analysis of marine crossover data. Geophysical Journal International 165:73-86

Chouet B (2003) Volcano seismology. PAGEOPH 160:739-788

Cooper AP, Smellie JL, Maylin J (1999) Evidence for shallowing and uplift from bathymetric records of Deception Island, Antarctica. Antartic Science 10:455-461

De Siena L, Del Pezzo E, Bianco F, Tramelli A (2009) Multiple resolution seismic attenuation imaging at Mt. Vesuvius. Physics of the Earth and Planetary Interiors 173:17-32

De Siena L, Del Pezzo E, Bianco F (2010) Seismic attenuation imaging of Campi Flegrei: Evidence of gas reservoirs, hydrothermal basins and feeding systems. Journal of Geophysical Research 115

De Siena L, Del Pezzo E, Thomas C, Curtis A, Margerin L (2013) Seismic energy envelopes in volcanic media: in need of boundary conditions. Geophysical Journal International 195 (2):1102-1119

De Siena L, Thomas C, Aster R (2014) Multi-scale reasonable attenuation tomography analysis (MuRAT): an imaging algorithm designed for volcanic regions. Journal of Volcanology and Geothermal Research 277:22-35

Del Pezzo E (2008) Seismic wave scattering in volcanoes. Advances in Geophysics 50:353-371

Del Pezzo E, Bianco F, De Siena L, Zollo A (2006) Small scale shallow attenuation structure at Mt. Vesuvius. Physics of the Earth and Planetary Interiors 157:257-268

Eberhart-Phillips D, Reyners M, Chadwick M, Stuart G (2008) Three-dimensional attenuation structure of the Hikurangi subduction zone in the central North Island, New Zealand. Geophysical Journal International 174:418-434

Fernández-Ibáñez F, Pérez-López R, Martínez-Díaz JJ, Paredes C, Giner-Robles J, Caselli A, Ibáñez J (2005) Costa Recta Beach, Deception Island, West Antarctica: a retreated scarp of a submarine fault. Antartic Science 17:418-426

García-Yeguas A, Almendros J, Abella R, Ibáñez J (2010) Quantitative analysis of seismic wave propagation anomalies in azimuth and apparent slowness at Deception Island volcano (Antarctica) using seismic arrays. Geophysical Journal International pp doi: 10.1111/j.1365-246X.2010.04,864.x

Haberland C, Rietbrock A (2001) Attenuation tomography in the western central Andes: A detailed insight into the structure of a magmatic arc. Journal of Geophysical Research 106(B6):11,151-11,167

Hansen S, Thurber CH, Mandernach M, Haslinger F, Doran C (2004) Seismic Velocity and Attenuation Structure of the East Rift Zone and South Flank of Kilauea Volcano, Hawaii. Bulletin of the Seismological Society of America 94:1430-1440

Hunsen S, Smith RB, Waite GP (2004) Evidence for gas and magmatic sources beneath Yellowstone volcanic field from seismic tomographic imaging. Journal of Volcanology and Geothermal Research 131:397-410

Ibáñez J, Almendros J, Alguacil G, Morales J, Del Pezzo E, Ortiz R (1997) Eventos ssmicos de largo periodo en la isla decepcin: evidencias de una zona volcnica activa. Boletn de la RSEHN 93:103-110

Ibáñez J, Del Pezzo E, Morales J, Alguacil G, Almendros J, Ortiz R, La Rocca M, García A (2000) Seismovolcanic signals at Deception Island Volcano, Antarctica: wave field analysis and source modelling. Journal of Geophysical Research 135:13,905-13,931

Ibáñez J, Carmona E, Almendros J, Saccorotti G, Del Pezzo E, Abril M, Ortiz R (2003) The 1998-1999 seismic series at deception island volcano, antarctica. Journal of Volcanology and Geothermal Research 128:65-88

Jaxybulatov K, Shapiro NM, Koulakov I, Mordret A, Lands M, Sens-Schonfelder C (2014) A large magmatic sill complex beneath the toba caldera. Science 346:617-619

Julian BR, Ross A, Foulger GR, Evans JR (1996) Three-dimensional seismic image of a geothermal reservoir: the Geysers, California. Geophysical Research Letters 23:685-688

Julian BR, Pitt A, Foulger GR (1998) Seismic image of CO2 reservoir beneath a seismically active volcano. Geophysical Journal International 133:F7-F10

Koulakov I, Yudistira T, Luehr BG (2009) P, s velocity and vp/vs ratio beneath the toba caldera complex (northen sumatra) from local earthquake tomography. Geophysical Journal International 117(3):1121-1139 
Koulakov I, Bindi D, Parolai S, Grosser H, Milkereit C (2010) Distribution of Seismic Velocities and Attenuation in the Crust Beneath the North Anatolian Fault (Turkey) from Local Earthquake Tomography. Bulletin of the Seismological Society of America 100(1):207-224

Kusakabe M, Nagao K, Ohba T, Hun Seo J, Park S, Lee J, Park B (2009) Noble gas and stable isotope geochemistry of the thermal fluids from Deception Island, Antarctica. Antarctic Science 21:255-267

Kuznetsov P, Koulakov I (2014) The three-dimensional structure beneath the Popocatépetl volcano (Mexico) based on local earthquake seismic tomography. Journal of Volcanology and Geothermal Research 276:10-21

La Rocca M, Del Pezzo E, Simini M, Scarpa R, De Luca G (2001) Array analysis of seismograms for explosive sources: evidence for surface waves scattered at the main topographical features. Bulletin of the Seismological Society of America 91:219-231

Lees JM, Lindley GT (1994) Three-dimensional Attenuation Tomography at Loma Prieta: Inverting $t *$ for Q. Journal of Geophysical Research 99(B4):6843-6863

Luzón F, Almendros J, García-Jerez A (2011) Shallow structure of Deception Island, Antarctica, from correlations of ambient noise on a set of dense seismic arrays. Geophysical Journal International 185:737-748

Maestro A, Somoza L, Rey J, Martnez-Fras J, Lpez-Martnez J (2007) Active tectonics, fault patterns and stress field of deception island: a response to oblique convergence between the pacific and antartic plates. Journal of South American Earth Sciences 23:256-268

Martí J, Vila J, Rey J (1996) Deception island (bransfield strait, antarctica): an example of a volcanic caldera development by extensional tectonics. McGuire, W J, Jones, A P and Neuberg, J, eds Volcano instability on the Earth and other planets Special Publication of the Geological Society, London 110:253-265

Martí J, Geyer A, Aguirre-Díaz G (2013) Origin and evolution of the Deception Island caldera (South Shetland Islands, Antarctica). Bulletin of Volcanology 75:732-750

Muñoz Martín A, Catalan M, Martin J, Carbo A (2005) Upper structure of Deception Island area (Bransfield Strait, Antarctica) from gravity and magnetic modelling. Antarctic Science 17:213-224

Martinez-Arevalo C, Bianco F, Ibáñez J, Del Pezzo E (2003) Shallow seismic attenuation and shear-wave splitting in the short-period range of Deception Island volcano (Antarctica). Journal of Volcanology and Geothermal Research 128:89-113

Matsumoto S, Uehira K, Watanabe A, Goto K, Iio Y, Hirata N, Okada T, Takahashi H, Shimizu H, Shinohara M, Kanazawa T (2009) High resolution $Q^{-1}$ estimation based on extension of coda normalization method and its application to $\mathrm{P}$-wave attenuation structure in the aftershock area of the 2005 West Off Fukuoka Prefecture Earthquake (M 7.0). Geophysical Journal International 179:1039-1054

Melo R, Vieira G, Caselli A, Ramos M (2012) Susceptibility modelling of hummocky terrain distribution using the information value method (Deception Island, Antarctic Peninsula). Geomorphology 155-156:88-95

Morozov IB (2011) Mechanisms of geometrical seismic attenuation. Annals of Geophysics $54(3)$

Muksin U, Haberland C, Bauer K, Weber M (2013) Three-dimensional upper crustal structure of the geothermal system in Tarutung (North Sumatra, Indonesia) revealed by seismic attenuation tomography. Geophysical Journal International 195, doi: 10.1093/gji/ggt383:2037-2049

Ohlendorf SJ, Thurber C, Pesicek JD, Prejean SG (2014) Seismicity and seismic structure at okmok volcano, alaska. Journal of Volcanology and Geothermal Research 278:103-119

Ortiz R, García A, Aparicio A, Blanco I, Felpeto A, Del Rey R, Villegas MT, Ibáñez J, Morales J, Del Pezzo E, Olmedillas J, Astiz MM, Vila J, Ramos M, Viramonte JG, Risso C, Caselli A (1997) Monitoring of the volcanic activity of deception island, south shetland islands, antarctica (1986-1995). In: Ricci, CA (Ed) The Antarctic Region: Geological Evolution and Processes, Terra Antartica Publications, Siena pp pp. 1071-1076

Pedrera A, Ruíz-Constán A, Heredia N, Galindo-Zaldívar J, Bohoyo F, Marín-Lechado C, Ruano P, Somoza L (2012) The fracture system and the melt emplacement beneath the Deception Island active volcano, South Shetland Islands, Antarctica. Antarctic Science 24:173-182 
Prates G, Berrocoso M, Fernndez-Ros A, Garca A (2013) Enhancement of sub-daily positioning solutions for surface deformation monitoring at deception volcano (south shetland islands, antarctica). Bulletin of Volcanology 75:1-10

Priyono A, Suantika G, Widiyantoro S, Nugraba AD (2011) Three-dimensioanl seismic attenuation structure of Mt. Guntur, West Java, Indonesia. International Journal of Tomography and Simulation 17:17-28

Prudencio J, Ibáñez J, García-Yeguas A, Del Pezzo E (2013) Spatial distribution of intrinsic and scattering seismic attenuation in active volcanic islands, II: Deception island images. Geophysical Journal International 195 (3):1957-1969, doi: 10.1093/gji/ggt360

Saccorotti G, Almendros J, Carmona E, Ibáñez J, Del Pezzo E (2001) Slowness Anomalies from two dense seismic arrays at Deception Island volcano, Antarctica. Bulletin of Seismological Society of America 91:561-571

Sato H, Fehler MC, Maeda T (2012) Seismic Wave Propagation and Scattering in the heterogeneous Earth: Second Edition. Springer, New York, USA

Schurr B, Asch G, Rietbrock A, Trumbull R, Haberland CH (2003) Complex patterns of fluid and melt transport in the central Andean subduction zone revealed by attenuation tomography. Earth and Planetary Science Letters 215:105-119

Smellie JL (2001) Lithostraigraphy and volcanic evolution of deception island, south shetland islands. Antartic Science 13:118-209

Smellie JL, López-Martínez J, Headland RK, Hernández-Cifuentes F, Maestro A, Millar IL, Thomson JW (2002) Geology and geomorphology of Deception Island. Cambridge, British Antarctic Survey, p 77p

Takanami T, Selwyn Sacks I, Hasegawa A (2000) Attenuation structure beneath the volcanic front in northeastern Japan from broad-band seismograms. Physics of the Earth and Planetary Interior 121:339-357

Tejedo P, Gutirrez B, Pertierra LR, Benayas J (2014) Analysis of published scientific research from deception island, south shetland islands. Antarctic Science p doi:10.1017/S0954102014000455

Torrecillas C, Berrocoso M, Pérez-López R, Torrecillas M (2012) Determination of volumetric variations and coastal changes due to historical volcanic eruptions using historical maps and remote-sensing at Deception Island (West-Antarctica). Geomorphology 136:614

Torrecillas C, Berrocoso M, Felpeto A, Torrecillas M, García A (2013) Reconstructing palaeo-volcanic geometries using a Geodynamic Regression Model (GRM): Application to Deception Island Volcano (South Shetland Islands, Antarctica). Geomorphology 182:79-88

Vanorio T, Virieux J, Capuano P, Russo G (2005) Three-dimensional tomography from $\mathrm{P}$ wave and $\mathrm{S}$ wave microearthquake travel times and rock physics characterization of the Campi Flegrei Caldera. Journal of Geophysical Research 110(B03201):doi:10.129/2004JB003,102

Vila J, Martí J, Ortiz R, García A, Correig AM (1992) Volcanic tremors at deception island, south shetland islands, antarctica. Journal of Volcanology and Geothermal Research $53: 1-4$

Vila J, Correig AM, Martí J (1995) Attenuation source parameters at Deception Island (South Shetland Islands, Antarctica). Pure and Applied Geophysics 144:229-250

Yoshimoto K, Sato H, Ohtake M (1993) Frequency-dependent attenuation of P and S waves in Kanto area, Japan, based on the coda-normalization method. Geophysical Journal International 114:165-174

Zandomeneghi D, Barclay A, Almendros J, Ibáñez J, Wilcock WSD (2009) Crustal structure of Deception Island volcano from P-wave seismic tomography: tectonic and volcanic implications. Journal of Geophysical Research 114 
Surveys in Geophysics manuscript No.

(will be inserted by the editor)

\title{
The 3D attenuation structure of Deception Island (Antarctica)
}

\author{
J. Prudencio · L. De Siena · J. \\ M. Ibáñez • E. Del Pezzo • A. \\ García-Yeguas · A. Díaz-Moreno
}

Received: date / Accepted: date

\footnotetext{
J. Prudencio

Instituto Andaluz de Geofísica, University of Granada, Profesor Clavera 12, 18071 Granada, Spain

Dept. Fisica Teórica y del Cosmos, University of Granada, Fuentenueva S/N, 18001 Granada, Spain

INVOLCAN, Antiguo Hotel Taoro, Parque Taoro 22, 38400 Puerto de la Cruz, Tenerife, Spain

E-mail: janire@ugr.es

L. De Siena

University of Münster, Institut für Geophysik, Correnstrasse 24, Münster, 48149, Germany.

University of Aberdeen, School of Geosciences, Geology and Petroleum Geology, Meston

Building, King's College, Aberdeen AB24 3UE Scotland

Tel. +492518334725

Fax +492518336100

E-mail: lucadesiena@uni-muenster.de

J. M. Ibáñez

Instituto Andaluz de Geofísica, University of Granada, Profesor Clavera 12, 18071 Granada, Spain

Dept. Fisica Teórica y del Cosmos, University of Granada, Fuentenueva S/N, 18001 Granada, Spain

Istituto Nazionale di Geofisica e Vulcanologia, Sezione di Catania -Osservatorio Etneo, 95125

Catania, Italy

E. Del Pezzo

Istituto Nazionale di Geofisica e Vulcanologia, Sezione di Napoli -Osservatorio Vesuviano, Via Diocleziano 328, 80124 Naples, Italy

Instituto Andaluz de Geofísica, University of Granada, Profesor Clavera 12, 18071 Granada, Spain

A. García-Yeguas

Dept. Física Aplicada, University of Cádiz, Av. Duque de Nájera 18, 11002, Cádiz, Spain

Instituto Andaluz de Geofísica, University of Granada, Profesor Clavera 12, 18071 Granada, Spain

INVOLCAN, Antiguo Hotel Taoro, Parque Taoro 22, 38400 Puerto de la Cruz, Tenerife, Spain
} 
Abstract The seismic and volcanological structure of Deception Island (Antarctica) is an intense focus topic in Volcano Geophysics. The interpretations given by scientists on the origin, nature, and location of the structures buried under the island strongly diverge. We present a high-resolution 3D $P$-wave attenuation tomography model obtained by using the coda normalization method on 20.293 high-quality waveforms produced by active sources. The checkerboard and synthetic anomaly tests guarantee the reproduction of the input anomalies under the island down to a depth of $4 \mathrm{~km}$. The results, once compared with our current knowledge on the geological, geochemical, and geophysical structure of the region, depict Deception as a piecemeal caldera structure leant out of the Bransfield Trough. High attenuation anomalies contouring the north-eastern emerged caldera rim correlate with the locations of sediments. In our interpretation, the main attenuation contrast, which appears under the collapsed southeastern caldera rim, is related to the deeper feeding systems. A unique $P$-wave high attenuation sphericallike anomaly in the inner bay extends between depths of 1 and $3 \mathrm{~km}$. The northern contour of the anomaly coincides with the calderic rim both at 1 and $2 \mathrm{~km}$, while smaller anomalies connect it with deeper structures below $3 \mathrm{~km}$, dipping towards the Bransfield Trough. In our interpretation, the large upper anomaly is caused by a high-temperature shallow (1 to $3 \mathrm{~km}$ deep) geothermal system, located beneath the sediment-filled bay in the collapsed collapsed blocks, and heated by smaller, deeper contributions of molten materials (magma) rising from southeast.

Keywords Attenuation · Scattering · Tomography · Antarctica

\section{Introduction}

Deception Island (Fig. 1) be is considered as a laboratory for Volcano Geophysics due to the large number of multidisciplinary studies focused both on imaging its surface and deep structures and on monitoring its volcanic activity. Scientists have widely studied the origin and morphology of Deception Island, bringing formed general and local models (e.g. Martí et al 1996, 2013; Smellie et al 2002; Fernández-Ibáñez et al 2005; Maestro et al 2007; Barclay et al 2009; Melo et al 2012; Torrecillas et al 2012, 2013). The study of the seismic activity of the volcano is probably the most active and productive research line, as reported by Tejedo et al (2014). There are many results that help to better understand the dynamic and volcanological framework of the area as Vila et al (1992), Almendros et al (1997), Ibáñez et al (1997), Ibáñez et al

A. Díaz-Moreno

Instituto Andaluz de Geofísica, University of Granada, Profesor Clavera 12, 18071 Granada, Spain

Dept. Fisica Teórica y del Cosmos, University of Granada, Fuentenueva S/N, 18001 Granada, Spain

Spain 
(2000), Ibáñez et al (2003), Saccorotti et al (2001), Martinez-Arevalo et al (2003), Benitez et al (2007), Carmona et al (2010), Carmona et al (2012), Carmona et al (2014) and García-Yeguas et al (2010). and seismic activity of the island. The velocity, attenuation, and magnetotelluric structures have on of the objetives of these seismic studies is to provide 2- or 3-D structure of the area, by using active or passive data as has been done by (Ben-Zvi et al 2009; Zandomeneghi et al 2009; Prudencio et al 2013). These seismic models have been used to confirm or help to built other geophysical or geodinamic models of the island, as magnetotelluric (Pedrera et al 2012), geomagnetic (Muñoz Martín et al 2005), gravimetric (Catalan et al 2006) or geodetic (Berrocoso et al 2012; Prates et al 2013). Aditionally, geochemical analysis as the composition and ratio of stable isotopes and gasses produced by fumaroles (Caselli et al 2004, 2007; Kusakabe et al 2009) are also very well know, and provide exact important information on the presence and origin of magma and fluids. All efforts still fril in creating a unique shod structural and dynic molof

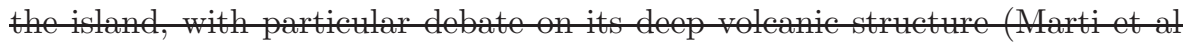
2013; Torrecillas at 2013). This de fouses on the presencend location either of a fractured geothermal system or a shallow, active magma chamber bener the sediment filled bay in the center of the wanic island as well as en its connections with deeper structures. Nowadays with these observables the research community is working to provide a geodinamic and volcanological model that could unify all of them in a single interpretation as those done by (Smellie 2001; Martí et al 2013; Berrocoso et al 2012; Pedrera et al 2012).

The imaging of region-specific velocity and attenuation through directwave tomography provides striking results at local, regional, and global scales (e.g., Schurr et al 2003 and Eberhart-Phillips et al 2008). Attenuation tomography is today a standard technique and several codes include this important measurement in their tomographic algorithms (Lees and Lindley 1994; Schurr et al 2003; Hansen et al 2004; Eberhart-Phillips et al 2008; Koulakov et al 2010). Due to the higher sensitivity of the attenuation parameters to the presence of fluids and melt with respect to velocity, attenuation tomography may provide decisive data to discriminate the location and nature of the volcanic and seismic structures under Deception Island.

The modeling of energy (amplitude) propagation in highly-heterogeneous local-scale volcanic media is especially complicated by frequency-dependent source and site effects. In these media, scattering phenomena produce highfrequency long wave-trains of incoherent radiation (coda waves, e.g., Sato et al 2012), affected by dispersion as well as by interference, diffraction, and resonant effects. The coherency in the corresponding direct signals is also quickly lost (La Rocca et al 2001; Chouet 2003; De Siena et al 2013). In these media, we may retrieve $P$ - and $S$-wave attenuation parameters independently of the site and instrumental transfer functions by using the coda-normalization method (Aki and Richards 1980; Yoshimoto et al 1993; Sato et al 2012). In recent years, this method has been applied to $S$-wave attenuation tomography at local scale, exploiting the strong scattering effects produced by strong het- 
erogeneity in volcanic regions (Del Pezzo et al 2006; Matsumoto et al 2009; Sato et al 2012; De Siena et al 2010).

The coda-normalization method is based on the equation that correlates the ratio between the S-wave direct energy and the coda-wave energy to the spatial distribution of the inverse total quality factors calculated along the source-station ray-path (Del Pezzo et al 2006; De Siena et al 2009, 2014). If active sources are available, the spatial distribution of $P$-wave attenuation becomes the only unknown if the final coda-normalization inverse problem, that is, the method may be exploited at best.

In this study, we obtain the $P$-wave total quality factor $\left(Q_{p}\right)$, which measures the anelastic and scattering losses suffered by $P$-waves while propagating into the medium. This quantity provides information on the physical, chemical, and geological state of the Earth, and becomes especially useful if compared with seismic velocities. A wide range of physical properties must be considered before discussing the joint results of velocity and attenuation tomography. Their combined interpretation is a decisive tool in discriminating volumes either permeated by fluids or characterized by structural discontinuities (Schurr et al 2003; Eberhart-Phillips et al 2008; De Siena et al 2010).

The relation between velocity and attenuation is often ambiguous. High attenuation and low velocity do not always mean the presence of melt in volcanoes, as fluids, gasses, faults, and, more generally, unconsolidated materials (like sediments) all produce high attenuation in the presence of different velocity signatures (Haberland and Rietbrock 2001; Schurr et al 2003; Hansen et al 2004; De Siena et al 2010; Muksin et al 2013). Several authors (e.g., Priyono et al 2011) suggest that high $\triangle Q_{p}^{-1}$ and low $\Delta V_{p}^{-1}$ in volcanic regions are related to a magmatic system, while others (e.g., Takanami et al 2000) relate these correlation to high-temperature zones without partial melting.

The $P$-to- $S$ velocity ratio $\left(V_{p} / V_{s}\right)$ is a decisive parameter to discriminate magma from either fluids or gasses if spatially correlated with high attenuation (Hansen et al 2004; Vanorio et al 2005; De Siena et al 2010; Kuznetsov and Koulakov 2014). Low $V_{p} / V_{s}$ anomalies and high attenuation may in fact be associated with the presence of gas filling faults and fractures, hydrothermal basins, and $\mathrm{CO}_{2}$ emission beneath volcanoes, mountain ranges, and geothermal reservoirs (Julian et al 1996, 1998; Hunsen et al 2004; Hansen et al 2004). The correlation of high $V_{p} / V_{s}$ with high attenuation is critical to discriminate fluids from melt. As no $V_{p} / V_{s}$ ratio information is available at Deception Island other geophysical, geological, and geochemical information must be considered with care in the final interpretation.

The aim of this study is to obtain reliable 3D frequency-dependent $P$-wave attenuation images of the upper $4 \mathrm{~km}$ beneath Deception Island (South Shetland archipelago, Antarctica) by using a subset of the waveforms employed by Ben-Zvi et al (2009) and Zandomeneghi et al (2009) to obtain velocity tomography results. We will provide new evidences that can be used in the future in a new geophysical interpretation by the comparison of the velocity and attenuation results with the current and new scientific results focused on the formation and structure of the Island. 
may discriminate the ffects callo by sediments, fluids, cracks, and partially med materials on the acty and at inages in order to shade light on the structures foeding this volcanic area.

2 Deception Island: controversial interpretations

\section{Deception Island: volcanological and geophysical models}

Deception Island is an active volcanic island composed by rocks that date to less than $0.75 \mathrm{Ma}$ and which suffered several historical eruptions in the last two centuries (Smellie 2001) (Fig. 1) . Nowadays its volcanic activity mainly consists of hot hydrothermal waters, fumarolic fields, and intense seismic activity composed by volcanic tremor, persistent long-period and volcano-tectonic seismicity (Vila et al 1992; Ortiz et al 1997; Ibáñez et al 2000; Carmona et al 2012).

The am of information the $1 \mathrm{~km}$

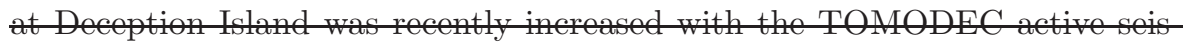
mic (o.g.,Z al 2009). Ben Z al 2009 and Zan tom al 2009 use this wast dat $2 \mathrm{D}$ and $3 \mathrm{D}$ images of $P$ wave velocity structure in the entire area between depths of 0 to $10 \mathrm{~km}$. Their results show strong deep (dow to $8 \mathrm{~km}$ ) latol wo rations, which are attributed to the presence of crustal magmatic systems with either partial melt regions and frozen intrusive bodies or sediment thickness varia a sy stom

A large high volocity anom intersects the northwestern part of Deception Island (Telefon Bay, Fig. 1) and is associated with the crystalline basement of the South Shotland Istands platform (Z al 2012). The main feature of the velocity models, however, is an extended low

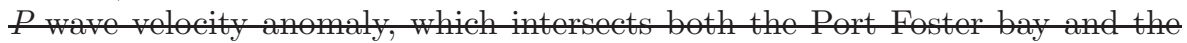

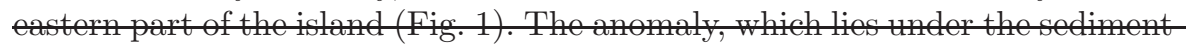
fill basin in the of the istand, sulmod by thecen, is in as the imag of an Zandomeghi al 2009). Lopes al (2014) suggest that Decon Island was actually formed above a magma chamber stretched under the influence of the regional transtensional regime with left lateral simple shear. The caldera eollapse may have occurred in at least two phases. A small volume event oc

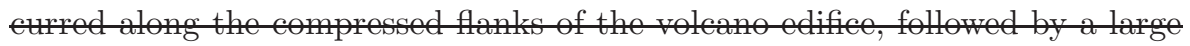
eollapse event, which affected the stretched flanks of the voleano edifice.

The influe of a shallow ma ham still be deted with seis mic observations, as the ones in apparent slowness and azimuth obtained by Garcia Yet al (2010) by using seismic arays and at data. These authors admit that several details of their analysis remain unexplained for a

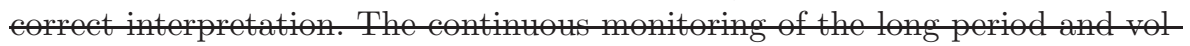
eano tectonic seismicity betw 1990 and 2011 by means of array analyses shor in fact the infor of the 
land may be associat with the ring fracture system bordering the collapsed ealdera structure, that extends over the inner part of the island (Ibainez at at 2000; Saccorotti et al 2001; Carmona et al 2012).

Pegarding seimic atemation, Vila al (1995) obtained locat at mution paramers from both cold andysis and source paramers information. The authors show abnormally low coda-Q values characterized by high frequency dependence in the inner bay of the island. They do interpret it as due to hot magmatic intrusion produced during the most recent eruption, but the width of this intrusion is estimat do benly out $0.2 \mathrm{~km}$. Morecently Martínez Arevalo et al (2003) estimated the seismic attenuation of both $P$ and $S$ waves at Deception Island, observing a predominance of satering orer intrinsic atenution. They do interpret these results as prol by a zon of streng hetergeneity, as done in most valcanic areas (Dep Pezze al 2008), where the presence of magma patches cannot be excluded.

Prudencio et al (2013) obtrined the regional 2D distribution of intrinsic and seatering a nution of the Istand by using the same form dataset employ to image its velocity structure and the diffusion eonfirm the presence of a high seatering atemation body below the inner

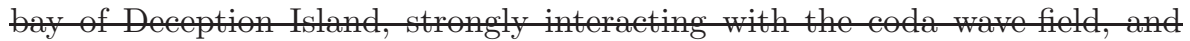
which may be associated with magma.

Munoz Martin et al (2005) and Pedrera et al (2012) carried out magnetolluric and grametric surven the island. The $3 \mathrm{D}$ resistivity mols of Pedrera et al (2012) reveal an elongate conductor between 2 and $10 \mathrm{~km}$ east of Whaters Bay (Fir. 1), which they interpres as ind by ambination of partial melt and hot fluids. The inferred deep magma sill is connected to the surface by arge resistive pathending mar Port Foster, spatially correlated with the velocity anomaly, and interpreted as a shallow magma chamber.

The above observations all support or, at least, consider the hypothesis of a-shallow magma chamber beneath the center of the bay. Hower, new field data as well as a review of older seismically related measurements (e.g., seismic profiles, local and regional seismicity, ete.) confutes this hyposis Marti et al (2013). The a thors show that a polygonal structural net consisting of seval pre existing major normal fauls controlled pre and post caldera volenism on the island: hence, recenterutions ho ben fod by small batehes of deeper source magma. In this interpretation, eruptive intrusions provide the min hert source that sustains the current geothermal system inside its depression, which may be responsible for most of the present day observations.

The studies supporting the existence of a shallow magma chamber under Deception also recognize the relerance of hydrothermal activity on their orea physical and geological results. For example, Luzón et al (2011) obtain images of the shallow surfor of Deeption Island by using correlations of ambient seismic noise. The results show that the voleano is eompes of seft layers of pyrolastic depesits and sediments extending to a depth of about $400 \mathrm{~m}$, while the deeper structure is highly variable in terms of vecities and layer depths; largest S w w w 


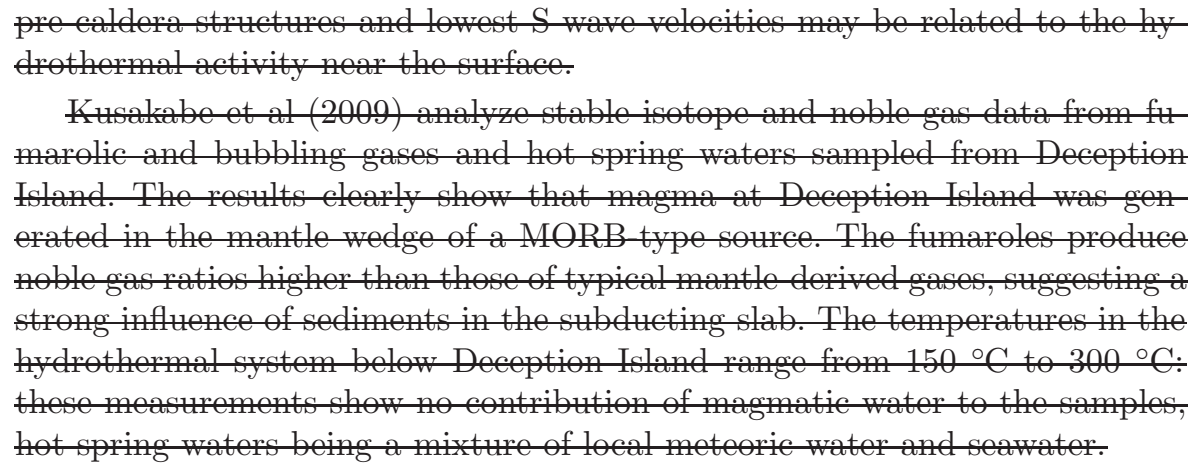

As indicated above, many of the present efforts of several researchers are focused in the interpretation of the geophysical, geodetic and geochemical observations in terms of structural and volcanological framework of the volcano to understand its past and to infer a possible evolution and volcanic dynamic. These researchers integrated seismic observations, mainly low and high seismic velocities and contrast in attenuation, conductivity, gases and geodetical information. On the base of these observations there are mainly at the present two possible models that are coincident in the interpretation of the shallower structure $(0-2 \mathrm{~km})$ and they are in desagree in the interpretation of the deeper structure. In one of them the effects of fractured rocks and the existence of a geothermal system that hydrothermally altered the medium is detected up to $6 \mathrm{~km}$ depth (Martí et al 2013). In the other, the observed anomalies are interpreted as the effects of the presence of certain amount of melted rock/material with variable volume (e.g. Ben-Zvi et al 2009; Pedrera et al 2012; Muñoz Martín et al 2005).

\subsection{Deep Geothermal effect}

Recently, Martí et al (2013) on the base of new stratigraphy and petrological studies, with the revision of previous results proposed a model of the formation and internal structure of the Island. In reference to the present internal structure, the authors show that a polygonal structural network consisting of several pre-existing major normal faults controlled pre- and post- caldera volcanism on the island. They defend that the formation of the caldera caused the destruction of the associated magma chamber and hence, recent eruptions have been fed by small batches of deeper-source magma. In their interpretation, a large hydrothermal system developed in the interior of the depression using highly fractured pre-caldera basement and syn-caldera rocks. The authors suggested that the current hydrothermal system inside its depression, which may be responsible for most of the present-day observations up to $6 \mathrm{~km}$ depth.

\subsection{Existence of melted material}


Mostly of the geophysical and geodetic studies performed in the area observed the existence of high constrast of the physical properties studied and these anomalies have an evident presence in the central part of the island (bellow Port Foster). These anomalies extend up to 6-10 km depth and their interpretations include the existence of partial melted rocks at depths 2-10 $\mathrm{km}$.

Seismic velocity observations: Ben-Zvi et al (2009) and Zandomeneghi et al (2009) used the data-set provided by the TOMODEC active seismic experiment to obtain $2 \mathrm{D}$ and $3 \mathrm{D}$ images of $\mathrm{P}$-wave velocity structure in the entire area of Deception Island between depth of 0 to $10 \mathrm{~km}$. Their results show strong deep (down to $8 \mathrm{~km}$ ) lateral velocity variations, which are attributed to the presence of crustal magmatic systems with either partial melt regions and frozen intrusive bodies or sediment thickness variations and geothermal systems. The authors indentified a large high-velocity anomaly intersects the northwestern part of Deception Island (Telefon Bay, Fig. 1) that was associated with the crystalline basement of the South Shetland Island platform. However, the main feature of the velocity models is an extended low $\mathrm{P}$-wave velocity anomaly, which intersects both Port Foster bay and eastern part of the island (Fig. 1). The same authors interpret the shallow how velocity anomalies (0-2 $\mathrm{km})$ as the effect of sediment-filled basin, hydrothermal activities, fractured materials from the caldera collapse and others. Ben-Zvi et al (2009) (pp.78) on the base of numerical simulations observed that the velocity anomalies bellow $2 \mathrm{~km}$ depths are compatible with the presence of partial melted materials (up to 15 melted) and with a maximum volume of up $20 \mathrm{~km} 3$. Zandomeneghi et al (2009) agree this interpretation.

Seismic attenuation observations: Regarding seismic attenuation, Vila et al (1995) obtained local attenuation parameters from both coda analysis and source parameters information. The authors show abnormally low coda-Q values characterized by high frequency dependence in the inner bay of the island. They do interpret it as due to a hot magmatic intrusion produced during the most recent eruption, but the width of this intrusion is estimated to be only about $0.2 \mathrm{~km} 3$. More recently Martinez- Arevalo et al (2003) estimated the seismic attenuation of both $\mathrm{P}$ - and S-waves at Deception Island, observing a predominance of scattering- over intrinsic- attenuation. They do interpret these results as produced by a zone of strong heterogeneity, as done in most volcanic areas (Del Pezzo 2006), where the presence of magma patches cannot be excluded. Recently, Prudencio et al (2013) obtained the regional 2D distribution of intrinsic and scattering attenuation of the Island by using the same waveform dataset employed to image its velocity structure and the diffusion model. The authors confirm the presence of a high scattering attenuation body below the inner bay of Deception Island, strongly interacting with the coda wave-field, and which may be compatible with the existance of magma.

Gravimetric and magnetotelluric observations: Muñoz-Martin et al (2005) show a very low density anomaly in both magnetic and gravity anomaly maps of Deception Island. The authors interpreted this anomaly as a partially 
melted intrusive body and they estimated the top of this body at $1.7 \mathrm{~km}$ depth using Euler deconvolution techniques. The 3D resistivity models of Pedrera et al (2012) reveal an elongate conductor between 2 and $10 \mathrm{~km}$ east of Whalers Bay (Fig. 1), which they interpret as induced by a combination of partial melt and hot fluids. The inferred deep magma sill is connected to the surface by a large resistive path ending Port Foster, interpreted as a shallow magma chamber.

\section{Data, method, and inversion setting}

\subsection{Data and ray tracing.}

The waveforms used in this study are a subset of the ones used by Zandomeneghi et al (2009) to obtain 3D velocity images by using a shortest-time ray tracing and a LSQR algorithm inversion. The authors choose two different model parametrizations. The first grid has coarser parametrization $(250 \mathrm{~m})$, it is centered on Deception Island and extends $53 \mathrm{~km}$ from West to East (WE), $52 \mathrm{~km}$ from South to North (SN), and down to $12 \mathrm{~km}$ depth. A smaller grid of $100 \mathrm{~m}$ step includes Port Foster and the nearest surroundings, and extends 12 $\mathrm{km}$ WE, $14 \mathrm{~km} \mathrm{SN}$, and down to $7 \mathrm{~km}$ depth. In order to compare the velocity and attenuation models we use a grid having the same lateral extension of the first grid in Zandomeneghi et al (2009).

Amplitude data are strongly frequency dependent. We show four recordings produced by a shot in the center of the bay (blue star) and registered at stations M, F, J, and H (Fig. 2). The stations record waveforms with excellent signalto-noise ratios (larger than 10) for the entire signal above $8 \mathrm{~Hz}$ only. However, both Vila et al (1995) and Prudencio et al (2013) show abnormallylow attenuation values at high frequencies in the Port Foster bay, where we focus our attention. Due to this strong attenuation we cannot provide reliable attenuation models of structures as deep as $4 \mathrm{~km}$ at frequencies larger than $10 \mathrm{~Hz}$.

We obtain the attenuation model after filtering data in the 4-8 frequency band (6 Hz central frequency). Considering the lowest measured velocities in the inner bay, the signal wavelenght associated with this frequency band safely allows to depict structures of the order of $1 \mathrm{~km}$ dimension at $4 \mathrm{~km}$ depth. As shown by Prudencio et al (2013) this frequency band also provides stable results for the measurements of both intrinsic and scattering attenuation from coda wave data. large uncertainties

We use the same Thurber-modified ray-bending approach described, e.g., by De Siena et al (2010) in the 3D sparse velocity model of Zandomeneghi et al (2009) (Fig. 3). The ray crossing at $5 \mathrm{~km}$ depths is still adequate for a tomographic approach (Fig. 3) but the increased linearity of the rays sums to the strong dispersion of coherent information with increasing depth. space density of the rays at depth of $5 \mathrm{~km}$ is still sufficient for correctly performing the tomography inversion (Figure 3). On the other hand, observational data associated with these paths show highly incoherent estimates even for paths 
crossing almost the same volumes. Therefore, our analysis and final interpretation is restricted to depths of 1 to $4 \mathrm{~km}$ : these analysis may provide hint on deeper structures once compared with other measurements.

\section{$3.2 P$-wave attenuation tomography with the coda normalization method}

The coda-normalization $(\mathrm{CN})$ method has been first applied to the singlestation estimate of the total S-wave inverse quality factor $Q$ along the seismic path by Del Pezzo et al (2006) in the Mount Vesuvius volcanic area. The single-path attenuation is obtained in a given frequency range with central frequency $f_{c}$ by measuring the direct-S energy $\left(E_{k}^{s}\right)$ and the coda-S energy in a time window centered around a given lapse time $t_{c}\left(E_{k}^{c}\left(f_{c}, t_{c}\right)\right)$, and calculating their ratio. The single-path $\mathrm{CN}$ equation is:

$$
\frac{1}{\pi f_{c}} \ln \left(\frac{E_{k}^{s}\left(f_{c}\right)}{E_{k}^{c}\left(f_{c}, t_{c}\right)}\right)=K\left(f_{c}, t_{c}, \theta, \phi\right)-\frac{2}{\pi f_{c}} \gamma \ln \left(r_{k}\right)-2 \int_{r_{k}} \frac{d l}{v(l) Q(l)}
$$

where $r_{k}$ is the total length of the $k^{t h}$ ray, $\gamma$ is the geometrical spreading, and $v(l)$ is the velocity of the medium measured along the ray-path. $K\left(f_{c}, t_{c}, \theta, \phi\right)$ takes into account the effect of the source radiation pattern, described by the take-off angle $(\theta)$ and azimuth $(\phi)$ and is the only other unknown variable (apart for $Q$ ) in the equation. As in given frequency bands diffraction effects, waveguides, and surface waves could affect the exponent $\gamma$ of the geometrical spreading we choose to invert this parameter with the inverse average quality factor (La Rocca et al 2001; Morozov 2011; De Siena et al 2014).

As shown by Yoshimoto et al (1993) we can extend the CN method to the measurement of $P$-wave average attenuation (the $P$-wave quality factor, $Q_{p}$ ). We use active sources, that is, only $P$-waves are produced. We can reasonably assume a spherical source radiation pattern, hence, $K\left(f_{c}, t_{c}, \theta, \phi\right)=K\left(f_{c}, t_{c}\right)$, leaving $Q_{p}$ as the only unknown in the inversion problem. We can thus apply the $\mathrm{CN}$ method to $P$-wave attenuation tomography under three assumptions:

- the small $P$ - and $S$-wave mean free paths in the volcanic structures allow for a quick conversion of $P$-wave energy into coda energy,

- the seismic paths traveled by the waves producing the energy ratios filtered in the chosen frequency band can be approximated by a ray (curve),

- the lapse-time from origin is large enough to measure coda energy out of the $P$-wave transient regime.

The energy ratios vs. travel times behaviour reveal no evident anomalous energy-ratio increase localized in space at $6 \mathrm{~Hz}$, indicative of anomalous coherent effects in the coda envelopes (De Siena et al 2014). As the lapse time $t_{c}$ strongly influences the estimates of the average parameter if it is set to short lapse-times (Calvet and Margerin 2013) we set the start of the coda time-window of length $3 \mathrm{~s}$ to a lapse-time of $12 \mathrm{~s}$. The $P$-energy time window is set to $1.5 \mathrm{~s}$. The waveforms were selected depending on the coda-to-noise ratio (always larger than 1.5) at $6 \mathrm{~Hz}$. 
The final data-set is comprised of 20293 vertical seismic waveforms. The inversion of the energy ratios for the average parameters provides an average $Q_{p}$ of 29: in the following we will discuss the variations with respect to the inverse of the average quality factor in the $3 \mathrm{D}$ space $\left(\Delta Q_{p}^{-1}\right)$, a direct measurement of attenuation. By considering these observations as well as the ideal distribution of our sources we invert the energy ratios for the attenuation parameters with the MuRAT code in a single-step inversion (De Siena et al 2014).

\section{Synthetic tests}

We want to discriminate the resolution we effectively achieve on a high attenuation anomaly in the center of the bay down to $4 \mathrm{~km}$ depth (Fig. 4). We start testing the resolution of the $\Delta Q_{p}^{-1}$ results assuming as input synthetic anomaly a high attenuation region in the centre of the island, roughly designed on the results of the velocity tomography (Figure 4, high attenuation correlated with high velocity). Hence, we impose a $8 \times 8 \times 4 \mathrm{~km}^{3}$ volume of low quality factor under Port Foster. We generate synthetic $P$-to-coda energy ratios and we add Gaussian random error with zero mean and 3 times the standard deviation, equal to the $20 \%$ of the data value. We invert the synthetic data only in blocks crossed by at least 5 rays. We show the results on four horizontal slides at different depths (Fig. 4).

In order to test the resolution in the entire region we also perform a checkerboard test, whose output is shown on the same 4 horizontal slices used in Fig. 4 (Fig. 5, third column). We add the same amount of Gaussian random error to the synthetic $P$-to-coda energy ratios calculated from a checkerboard synthetic structure with $2 \mathrm{~km}$ node spacing, starting at $0 \mathrm{~km}$, and having quality factors equals either to 100 or 1000 . The checkerboard and synthetic anomaly test inputs and outputs are also shown on SN and WE vertical sections, crossing the inner bay (Fig. 3, dotted gray line).

The checkerboard test results are well resolved everywhere between depths of 1 and $3 \mathrm{~km}$, while smearing affects the output at $4 \mathrm{~km}$ depth, especially in the regions contouring the island (Fig.s 5). The synthetic anomaly test is well resolved down to $4 \mathrm{~km}$ depth except for some smoothing on the southern and western sides of the images, between depths of 1 to $3 \mathrm{~km}$ (Fig.s 4 and 6). We conclude that we have good resolution in the volume under study. Also, a high attenuation anomaly, located in the center of the bay and as deep as 4 $\mathrm{km}$, can be obtained by the inversion of real data.

\section{Results and joint interpretation with the geological and geophysical results.}

Fig. 5 shows 4 horizontal slices through the velocity and attenuation models down to a depth of $4 \mathrm{~km}$ (left-hand and central columns). Fig. 6b,c shows two vertical sections of these models, following the WE and SN directions as 
shown in Fig. 3 (gray dotted line). The $P$-wave percent velocity variations $\left(\% \Delta V_{p}\right)$ are calculated by the $P$-wave velocity model of Zandomeneghi et al (2009). The interpretation of our results is based on the analysis of the largest attenuation anomalies in the regions of major volcanological interest (Fig. 7).

In order to correlate the velocity and attenuation anomalies with those obtained by other geophysical and geological studies we discuss the results under the Oceanic Crust and ealderic rim caldera structure separately from the ones under the Port Foster. We also separate the discussion of the anomalies under Port Foster bay in two different depth ranges (between depths of 1 and $2 \mathrm{~km}$ and between depths of 3 and $4 \mathrm{~km}$ ).

\subsection{Oceanic Crust and caldera structure}

No unique high-attenuation anomaly larger than $2 \mathrm{~km}$ is visible under the Oceanic Crust contouring the island. An arc-shaped volume of small (2 km average dimension) high-attenuation anomalies is located northeast of Deception at a depth of $1 \mathrm{~km}$ (Fig. 5). This volume, located in a low-velocity zone, is partially visible in the $2 \mathrm{~km}$ tomograms. (Zandomeneghi et al 2009) interpret the vast superficial low-velocity anomaly northeast of the island (1 to $2 \mathrm{~km}$ depth, Fig. 5, left-hand column) as a zone of accumulation for sedimentary materials and hydrothermal activity. From the depth extension and location of the high-attenuation arc-shaped volume we confirm this interpretation, in the sense that the high attenuation anomaly may actually locate the inner boundary of the sedimentary structures and hydrothermal interactions.

Most of the source energy recorded near this boundary crosses the Port Foster bay, that is, the most attenuating structure in the entire region (Vila et al 1995; Martinez-Arevalo et al 2003). The fractured caldera as well as the faults contouring the inner bay may also reflect or diffract direct energy. Hence, we may not expect to image the exact lateral extension of these sediments: we may safely assume that velocity tomography provides more reliable information on these structures.

Under the south-south-eastern part of the caldera structure, which constitutes the part of Deception emerged out of the Ocean, we observe the largest attenuation contrast, marking the entire depth range (e.g., Fig.s 6c and $7 \mathrm{SN}$ ). The low attenuation visible under the caldera defines an almost vertical boundary with the high attenuation medium under Port Foster, in strong correlation with the location of deep normal faults. The southern part of Deception is also affected by large smearing (Fig. 6d), induced by the large velocity contrast affecting the deep geometry of each source-station ray passing through it.

Pedrera et al (2012) obtain a vast conductive body extending SE of the Island between depths of 2 and $12 \mathrm{~km}$. The authors suggest emplacement of melt in this volume driven by an ENE-WSW oriented and SSE dipping regional normal fault. An almost vertical low-velocity and high-resistivity anomaly between depths of 2 and $6 \mathrm{~km}$ is located below Port Foster, connecting the vast 
southeastern high-resistivity anomaly with the center of the island. The vertical attenuation contrast is laterally disposed above the northwestern limit of the deep high resistivity anomaly (Fig. 7).

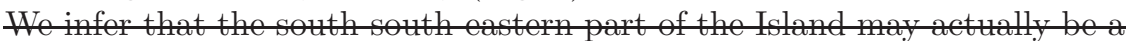
Alid/melt foling for the (Ben Z at al 2009; Zandomeghi et 2009; Pd 2012). Our results are compatible with previous studies (Ben-Zvi et al 2009; Zandomeneghi et al 2009; Pedrera et al 2012) affirming that the south-south-eastern part of the Island may contain a certain volume of a fluid/melt which may be the feeding path for the caldera. The section of this path, which should be connected to the center of the island and present high attenuation, reduces to our node spacing in the attenuation images at 4 km depth (Fig. 5, 4km). (2013) Additionally, our results are also compatible with other interpretation provided by Martí et al. (2013) in which the deep feeding structures may simply heat the upper crustal systems, where meteoric waters both penetrate and circulate producing the high-attenuation anomaly in the centre of the caldera (Fig. 7).

Deception faces the Bransfield Through from northwest (Martí et al 2013). The collapsed part of its caldera structure corresponds to the northwestern margin of the Through as well as to both steep almost-vertical normal faults and strong attenuation contrasts (Fig. 7, upper-right panel). Velocity and resistivity tomograms show clear low-velocity and high-resistivity connections of the upper anomalies with deeper vast high-resistivity regions, extending south-east of the island (Fig. 7, vertical section). system, through which fluids and melt materials either pass or heat the upper

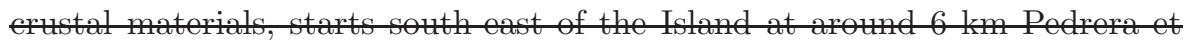
1(2012). Our results are in concordance with those obtained by Pedrera et al (2012) which suggested that the feeding system, through which fluids and melt materials either pass or heat the upper crustal materials, starts south-east of the Island at around $6 \mathrm{~km}$. The main connection with the surface rises almost vertically towards the southeastern margin of the Island (Zandomeneghi et al 2009; Pedrera et al 2012), passing through the high-attenuation contrasts southeast of the Island (Fig. 7). We discuss in the next two sections if, how, and where the deep melt materials (magma) are stored in the first $4 \mathrm{~km}$ under Deception.

\subsection{From depths of 1 to $2 \mathrm{~km}$ under Port Foster}

The Port Foster Bay (inner bay of Deception Island, Fig. 1) is dominated by a large $\triangle Q_{p}^{-1}$ positive anomaly, that is, by high attenuation, down to a depth of $2 \mathrm{~km}$ (Fig. 5, central column, red). In this depth range the high-attenuation volume is contoured by average-to-low attenuation structures, mainly corresponding to the exposed caldera rim (Figs. 5 and $6 \mathrm{c}$ ). Zandomeneghi et al (2009) and Luzón et al (2011) both propose that unconsolidated volcanoclastic and volcano-sedimentary materials, possibly producing high attenuation, extend down to $1.2-1.4 \mathrm{~km}$ depth. We remark, that the anomaly in 
the centre of the bay shows much higher attenuation than the surroundings. This is particularly relevant if we compare the results in the central bay with the arc of high attenuation located northeast of the island, where low velocities are also interpreted as induced by sediments (Zandomeneghi et al 2009).

The strong $P$-wave attenuation is paired with a strong scattering signature (obtained by Prudencio et al (2013) under the bay) and suggests that materials with higher attenuation capacity than sediments, like hydorthermal interations intrude the first $2 \mathrm{~km}$ depth under the Port Foster bay. The top of a resistivity anomaly obtained by Pedrera et al (2012) resembles pretty well the low velocity and high attenuation structure under the bay at a depth of $2 \mathrm{~km}$ (Fig. 5, see also Zandomeneghi et al (2009)). B Z Z and (2009) and Podrera al (2012) infer that their anomalies are mainly induced by a shallow magma fluid chamber.

Getting S-wave velocity information is important for the interpretation of the attenuation anomalies. The only measurements which may provide Hinformation on the frons 1 and $2 \mathrm{~km}$ are the surface wave velocities obtained by using noise measurements at

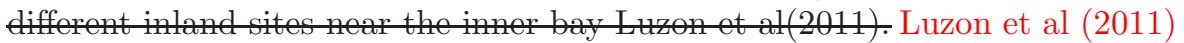
provide us information on the transverse velocity wave-field between depths of 1 and $2 \mathrm{~km}$. The lowest S-wave velocities (related in the interpretation of Luzón et al (2011) to the alterations produced by hydrothermal activity) are near Chilean station (Fig. 1) northeast of the bay. On the contrary, the largest velocities occur near the SW caldera border, revealing the presence of compact materials at shallow depths. The low velocity anomaly obtained by Luzón et al (2011) at $1 \mathrm{~km}$ matches with the high-attenuation unique anomaly shifted towards the north part of the bay.

De Siena et al (2010) depict zones of fluid accumulation coupled to a surrounding network of normal faults beneath Pozzuoli (Campi Flegrei, Italy), where the correlation of high attenuation and high $V_{p} / V_{s}$ anomalies (Vanorio et al 2005) is striking. This high attenuation anomaly is contoured by a hard rock volume and associated with the caldera rim structure: this image is very similar to the one we observe at Deception (compare our results with De Siena et al (2010), Fig. 7c, markers X4, X5, and X6). In De Siena et al (2010) the presence of melt is restricted to a small volume located at a depth of about $4 \mathrm{~km}$ embedded in a hard rock volume, and heating the geothermal system under Pozzuoli.

The lateral extension of the high attenuation anomaly at Deception is actually coincident with the bathymetry of the floor of the bay (Fig. 6a), which reveals a broad uplift of the eastern side of the caldera (Cooper et al 1999). As proposed by Barclay et al (2009) and remarked by Martí et al (2013) bathymetric results could be caused by sediment supply rates and hydrothermal alterations from the east of the island or by a trap-door caldera deformation with its minimum subsidence in the east. Both these causes are compatible with permeation of local meteoric water and seawater in the intra-caldera formation. 
Important indications on the bsence of a large magmatic chamber betwen deps of 1 to $2 \mathrm{~km}$ Other additional evidences of the nature of sediment deposits, volcanoclastic materials and hidrothermal alteration effects on the first $2 \mathrm{~km}$ shallow part of the caldera floor, is obtained by the study of some geochemical aspects of the area as the study of isotopes and noble gas data from fumarolic and bubbling gases and hot spring waters (Kusakabe et al 2009). $\mathrm{He}$ and $\mathrm{CO}_{2}$ are mainly of mantle origin, with no contribution of magmatic water to water and gas samples, hot spring fluids being a mixture of local meteoric water and seawater. Kusakabe et al (2009) infer that these results are due to the existence of a heated hydrothermal system, with different temperatures in the depth range between 1 and $2 \mathrm{~km}$.

The shape of the high attenuation anomaly, contoured by the low-attenuation caldera rim between depths of 1 and $2 \mathrm{~km}$ (Fig.s 5 and 6) is similar to the one retrieved under different calderas and associated with the presence of hydrothermal alteration. The large low-velocity and high-attenuation structure in the bay (Fig.s 5 and $6 \mathrm{~b}, \mathrm{c}$ ) correlates well with high resistivity, high scattering attenuation, and low S-wave velocities. If absence of magmatic water from water and gas samples we may infer that Therefore, attenuation anomaly shows a portion of the collapsed caldera center permeated by a geothermal reservoirs, at least between depths of 1 and $2 \mathrm{~km}$.

\subsection{From depths of 3 to $4 \mathrm{~km}$ under Port Foster}

Low velocity and high attenuation anomalies are less strong at depths larger than $2 \mathrm{~km}$ under Port Foster (Fig.s 5 and 6). The percent velocity variations show a continuous vertical anomaly between depths of 3 and $4 \mathrm{~km}$, while the high-attenuation anomaly is shaped as a sphericallike system having its basis approximately at $3 \mathrm{~km}$ depth (Fig. 6b,c). No large unique high-attenuation anomaly is visible at a depth of $4 \mathrm{~km}$ in the centre of the bay (Fig.s 5 and 6c). High-attenuation anomalies with lateral extensions of the order of our node spacing connect the upper high attenuation semispherical anomaly with depth. Our assumption is that seismic attenuation is more sensitive to the presence of deep melt and fluids than seismic velocity, while velocity tomography is able to sample larger depths (Hansen et al 2004; De Siena et al 2010; Muksin et al 2013).

In their 2D and 3D resistivity maps Pedrera et al (2012) also reveal an ENE-WSW elongated conductor located between 2 and $6 \mathrm{~km}$ depth beneath the Port Foster bay, which they interpret as induced by a combination of partial melt and hot fluids. The depth resolution of the magnetotelluric model, which defines quite precisely the top of melt/fluid regions, is affected by the resistivity of the superficial highly-resistive marine layers. This may cause an incorrect depth definition of the highly resistive structures. As in attenuation tomography we use ray-dependent measurements we assume we provide higher 
resolution than in magnetotelluric imaging, again at the expense of depth sampling.

The attenuation tomograms clearly show that the anomaly extends down to a maximum depth of $3 \mathrm{~km}$ as a unique hemispherical body. The depth extension and shape of the high attenuation anomaly at depths of 3 to $4 \mathrm{~km}$ is similar to the ones observed in other areas, e.g., by De Siena et al (2010) in the Campi Flegrei caldera, by Muksin et al (2013) in the Tarutung Basin, and by Bohm et al (2013) in the Kendeng Basin. These observations are always related to sedimentary or volcanoclastic deposits overlying active geothermal and gas reservoirs. However, other studies, interpret this high attenuation anomaly and low velocity body as the presence of shallow partial melted magma body such as Koulakov et al (2009) and Jaxybulatov et al (2014) in Toba caldera or Ohlendorf et al (2014) in Okmok Volcano. In Okmok volcano the authors found the same patterm of velocity and attenuation observed in Deception Island and they interpreted the shallow part of the anomaly (surface to $2 \mathrm{~km}$ ) as caldera fill, groundwater and small pods of magma and the deeper part of the anomaly (from 4 to $6 \mathrm{~km}$ ) as a magma storage zone. This geodynamic model is compatible with the subduction processes or slab rollback suggested by Maestro et al (2007).

We infer that the low velocity and high-resistivity conductor imaged by Zan (2009) and Polrera al (2012) b 3 and $6 \mathrm{~km}$ ac tually shows a feeding path of hot lower crustal or mantle materials (Fig. 7). Horer, the shap of the high atention anmaly as well as its maximmm extension to $3 \mathrm{~km}$ as a unique hemispherical body bordering the rim better fits an interpetion in terms of an active (Fig. 7). As indicated previously in section 2 and above, our results are compatible with both proposed models. The modelled volume of melted rocks of Ben-Zvi et al (2009) (less than 15-20 km3) in depht can coexist with other effects as a network of magma and fluid filled batches of size either lower than or equal to our resolution seems the more reliable explanation for the absence of a unique high attenuation anomaly down to 4 $\mathrm{km}$. This network could be visible as a unique velocity and conductive anomaly, which may provide the main heat source that sustains the geothermal system in the first $3 \mathrm{~km}$ of the crust (Martí et al 2013).

\section{Conclusions}

We obtain and interpret the $30 P$ a d tand by using different geophysical, geological, and geochemical observations, in order to discriminate the nature andextension of voleanological struetures, especially melt and fluid accumulation regions. Sediments filling the upper $\mathrm{km}$ northeast of the istand produce a small boundary approximaty following the alderam.

We infer that the strong attenuation contrast under the southeastern part of the istand shows the logtion and effects of normal faults, which drive 
melt/fuid materials in the upper $\mathrm{km}$ of the crust, and meteric eulation in the lower erust. A large resistivity anomaly haing its top been 5 and $6 \mathrm{~km}$ depth has its northwestern margin directly below this contrast. In this interpretation, between depths of 4 and $6 \mathrm{~km}$, highly resistive and low tocity anomalies still show the foeling path of the caldera. Hower, the at tenuation images exclude the presence of a large magma accumulation region at $4 \mathrm{~km}$.

The most relewnt anomaly in the atenution molel is the unique high attenuation spherical like structure beneath the Port Foster bay, its lateral

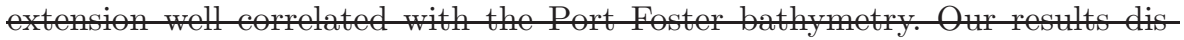
eriminate bo theral and depthension of either a magma or a fluidfilled zone centered benerth the northestern part of the submerged istand eenter. The anomaly has a maximum depth extension of $3 \mathrm{~km}$ and is generally associated with $P$ and $S$ wolocities, high resistivity, and high scatter ing attenuation. Hot spring waters collected near the anomaly are a mixture of local meoric ater and seawat, showing nommatic contribution. The 3D shape of the anomaly, contoured by the rim, is similar to the one observed in ther ealderas ond ormal systems.

The problem of assessing the presence (or absence) of magma in high at tenution anomalies is wivalent the problem of defining which percentage of magma should be contained in a structure to define it as a magma chamber. With our med are not able discriminte excly the perentages. Nevertheless, the results of our andysis let us lean tords an interpretion in terms of a crack medium filled with sediments and geothermal fluids in side the caldera depression with smaller percentages of magma, down to $3 \mathrm{~km}$ depth.

In our interpretation, the system is mainly her by smaller, deper magma related anomalies, loated inside the low velocity and high resistiv ity path below $3 \mathrm{~km}$. This path is poduced by the wast deep high resistivity region southeast of the island, and may provide the main path for deeper rising magma derived heat. In order to oither confirm or confut this interpre tation the addition of new geological, geophysical, and geochemical data (in particular spatial dels of $P$ to $S$ velocity ratio rarians) is eritieal.

In the present work we obtain the 3D P-wave attenuation model of Deception Island by using coda normalization method. The methodology used in this study is stable, robust and reliable. The reliability of the method is based on the similarity of results with other studies. The study of S-waves and $\mathrm{Vp} / \mathrm{Vs}$ distribution might better constrain the inner structure of the island.

We have provided new results showing the complex atenuative structure of the island with the presence of bodies of low and high attenuation. As in the velocity tomography, we find a limitation in the range of depth that we are able to solve due to the structure of the thinned oceanic crust region where the Moho is 4-5 km depth and it implies a physical barrier.

One of the most important remarks is the presence of high attenuation body in the center of the island which extends from the surface to our resolution limit. The interpretation of this anomaly in the first two kilometers agrees 
almost all researchers who have worked on the island and is associated with the effects of sedimentary and volcanoclastic deposits, hydrothermal interactions and highly fractured material.

The interpretation of the deeper structure is more complex, mainly due to the lack of S-waves data. Thus, our results are consistent with two possible models. In the first, the high attenuation and low velocity is due to a hydrothermal system effects. On the other, this anomaly is interpreted as the existence of a partially molten magmatic body. A combination of these two models is also compatible with our results. It will be necessary to continue working to incorporate data from $\mathrm{S}$ waves or other methodologies to give light to the interpretations.

\section{Fig. captions}

Fig. 1: Regional setting and location of Deception Island in the South Shetland Islands archipelago, Antarctica (upper two panels). Bottom panel: Toponyms (bold italics), historical eruption sites (white on black rectangle), and research stations active or destroyed by the recent eruptions (regular bold), are shown on the contour map of Deception Island.

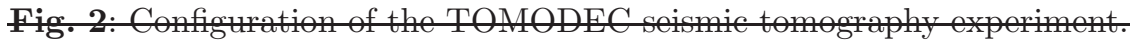
ฉ) Land and ocon botom seimometers (red triangles) and shots locations

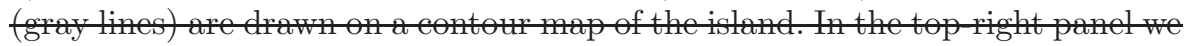
tzom on the on of the island (Port Foster bay). b): 3D and 2D sourcesta tion ray paths obtained by using a Thurber modified ray bending approach.

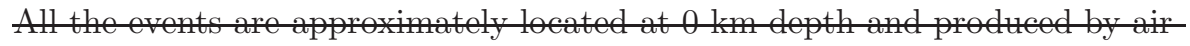
guns. The red contour map imposed on the rays shows the location and shape of Deception Istand with respect the experiment seting.

Fig. 3: The vertical records of a seismic shot produced on the 8 of January 2005, loat in the center of the Port Foster Bay (bluestar), and reorded at four seismic land stations (M, F, J, H). The gray dotted line crossing near the enter of the bay indicate the location and direction of the vertical sections shown in Fig. (6). The panels on the right show the signal spectrum (S, blue

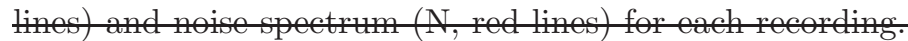

Fig. 2: The vertical records of a seismic shot produced on the 8 of January 2005, located in the center of the Port Foster Bay (blue star), and recorded at four seismic land stations (M, F, J, H). The gray dotted line crossing near the center of the bay indicate the location and direction of the vertical sections shown in Fig. (6). The panels on the right show the signal spectrum (S, blue lines) and noise spectrum (N, red lines) for each recording.

Fig. 3: Configuration of the TOMODEC seismic tomography experiment. a) Land and ocean bottom seismometers (red triangles) and shots locations (gray lines) are drawn on a contour map of the island. In the top-right panel we a zoom on the center of the island (Port Foster bay). b): 3D and 2D sourcestation ray-paths obtained by using a Thurber-modified ray-bending approach. All the events are approximately located at $0 \mathrm{~km}$ depth and produced by air- 
guns. The red contour map imposed on the rays shows the location and shape of Deception Island with respect to the experiment setting.

Fig. 4: Upper panel: The synthetic anomaly test input is designed to show the reproducibility of a simplified deep high-attenuation anomaly under the Port Foster bay. The high attenuation anomaly has a dimension of $8 \times 8 \times 4 \mathrm{~km}^{3}$ and is characterized by a quality factor of 3 . Lower panels: four horizontal slices through the output of the synthetic anomaly test taken at different depths with respect to the sea level. The $\triangle Q_{p}^{-1}$ grey scale shows the variations with respect to the average quality factor.

Fig. 5: The results of velocity tomography (Zandomeneghi et al 2009, lefthand column), of the attenuation tomography (central column) and the output of the checkerboard test (right-hand column) are shown on four horizontal slices taken at different depths. The left-hand color scale shows the percent variations of the velocity model with respect to its average. Both the central color scale and the right-hand grayscale show the variations of the attenuation model with respect to the average quality factor. The contour of Deception Island is over-imposed on each panel.

Fig. 6: Bathymetry (a), velocity model (Zandomeneghi et al 2009, b), attenuation model (c), and the synthetic tests (d) are all shown on two vertical sections crossing the Island (gray dotted lines in Fig. 3). The vertical scale in the velocity and attenuation images is enlarged for clarity. b) The color scale shows the percent variations of the velocity model with respect to its average. c) The color scale shows the variations of the attenuation model with respect to the average quality factor. d) The $\triangle Q_{p}^{-1}$ grey scale shows the variations with respect to the average quality factor. The inputs are shown above the corresponding outputs for both the checkerboard test and the synthetic anomaly test. The input of the synthetic anomaly test is described in the caption of Fig. 4.

Fig. 7: Schematic interpretation of the attenuation model, carried out with reference to the 3D velocity (Zandomeneghi et al 2009) and resistivity (Pedrera et al 2012) models, and constrained by other geophysical, geological, and geochemical observations, as described in the text. In the upper-right panel we show a horizontal section of the region taken at $8 \mathrm{~km}$ depth and depicting the portion of the Bransfield Through as well as the horizontal contour of the high resistivity anomaly contained in the region under study. We also infer from our analysis both meteoric water circulation in the upper crust and heat rising towards surface. We depict the depth dependence of the anomalies described in the text on two vertical sections, taken between depths of 0 and $10 \mathrm{~km}$ and crossing the Island (gray dotted lines in Fig. 3). Below a depth of $4 \mathrm{~km}$ the sketch is based on the $3 \mathrm{D}$ velocity and resistivity results only. Below $5.5 \mathrm{~km}$ the sketch is based on the resistivity model only.

Acknowledgements We gratefully acknowledge editor Dr Rycroft, Prof. Martí and one anonymous reviewer whose useful suggestions greatly improved the manuscript. This work has been partially supported by the Spanish project Ephestos, CGL2011-29499-C02-01; by the EU project EC-FP7 MEDiterranean SUpersite Volcanoes (MED-SUV); by the Basque 
Government researcher training program BFI09.277 and by the Regional project 'Grupo de Investigacin en Geofsica y Sismologa de la Junta de Andaluca, RNM104'. Edoardo del Pezzo has been partly supported by DPC-INGV projects UNREST, SPEED and V2 (Precursori). We also thank Christine Thomas, Ralf Hetzel, and Stephan Klemme for the important suggestions regarding both the method and the interpretation.

\section{References}

Aki K, Richards P (1980) Quantitative Seismology - Theory and Methods. W. H. Freeman, San Francisco

Almendros J, Ibez J, Alguacil G, Del Pezzo E, Ortiz R (1997) Array tracking of the volcanic tremor source at deception island, antarctica. Geophysical Research Letters 24:30693072

Barclay A, Wilcock WSD, Ibáñez J (2009) Bathymetric constraints on the tectonic and volcanic evolution of Deception Island Volcano, South Shetland Islands. Antarctic Science 21:153-167

Ben-Zvi T, Wilcock WSD, Barclay A, Zandomeneghi D, Ibáñez J, Almendros J (2009) The $\mathrm{P}$ wave velocity structure of Deception Island, Antarctica, from two dimensional seismic tomography. Journal of Volcanology and Geothermal Research 180:67-80

Benitez MC, Ramrez J, Segura JC, Ibez J, Almendros J, Garca-Yeguas A, Corts G (2007) Continous hmm-bases seismic-event classification at deception island, antarctica. Geoscience and Remote Sensing, IEEE Transactions 45:138-146

Berrocoso M, Prates G, Fernndez-Ros A, Garca A (2012) Normal vector analysis from gnss-gps data applied to deception volcano surface deformation. Geophysical Journal International 190:1562-1570

Bohm M, Haberland C, Asch G (2013) Imaging fluid-related subduction processes beneath Central Java (Indonesia) using seismic attenuation tomography. Tectonophysics 590:175-188

Calvet M, Margerin L (2013) Spatial variations of seismic attenuation in the Pyrenees: coda Q and peak delay time analysis. Bulletin of Seismological Society of America 103:doi:10.1785/0120120,239

Carmona E, Almendros J, Pea JA, báez JM (2010) Characterization of fracture systems using precise array locations of earthquake multiplets: An example at Deception Island volcano, Antarctica. Journal of Geophysical Research: Solid Earth 115

Carmona E, Almendros J, Serrano I, Stich D, Ibáñez J (2012) Results of seismic monitoring surveys of Deception Island volcano, from 1999-2011. Antarctic Science 24:485-499

Carmona E, Almendros J, Martn R, Corts G, Alguacil G, Moreno J, Martn JB, Martos A, Serrano D Ia dn Stich, Ibez J (2014) Advances in seismic monitoring at deception island volcano (antarctica) since the international polar year. Annals of Geophysics 57

Caselli A, Santos-Alfonso M, Agusto MR (2004) Gases fumarolicos de la isla Decepcion (Shetland del Sur, Antartida): Variaciones quimicas y depositos vinculados a la crisis sismica de1999. Asociación Geológica Argentina Revista 59:291-302

Caselli A, Badi G, Bonatto AL, Bengoa CL, Agusto MR, Bidone A, Ibáñez J (2007) Actividad sísmica y composición química fumarólica anómala debido a posible efecto sello en el sistema volcánico, Isla Decepción (Antártida). Revista de la Asociación Geológica Argentina 62:545-552

Catalan M, Agudo LM, Muoz-Martin A (2006) Geomagnetic secular variations of Bransfield Strait (Western Antarctica) from analysis of marine crossover data. Geophysical Journal International 165:73-86

Chouet B (2003) Volcano seismology. PAGEOPH 160:739-788

Cooper AP, Smellie JL, Maylin J (1999) Evidence for shallowing and uplift from bathymetric records of Deception Island, Antarctica. Antartic Science 10:455-461

De Siena L, Del Pezzo E, Bianco F, Tramelli A (2009) Multiple resolution seismic attenuation imaging at Mt. Vesuvius. Physics of the Earth and Planetary Interiors 173:17-32 
De Siena L, Del Pezzo E, Bianco F (2010) Seismic attenuation imaging of Campi Flegrei: Evidence of gas reservoirs, hydrothermal basins and feeding systems. Journal of Geophysical Research 115

De Siena L, Del Pezzo E, Thomas C, Curtis A, Margerin L (2013) Seismic energy envelopes in volcanic media: in need of boundary conditions. Geophysical Journal International 195 (2):1102-1119

De Siena L, Thomas C, Aster R (2014) Multi-scale reasonable attenuation tomography analysis (MuRAT): an imaging algorithm designed for volcanic regions. Journal of Volcanology and Geothermal Research 277:22-35

Del Pezzo E, Bianco F, De Siena L, Zollo A (2006) Small scale shallow attenuation structure at Mt. Vesuvius. Physics of the Earth and Planetary Interiors 157:257-268

Eberhart-Phillips D, Reyners M, Chadwick M, Stuart G (2008) Three-dimensional attenuation structure of the Hikurangi subduction zone in the central North Island, New Zealand. Geophysical Journal International 174:418-434

Fernández-Ibáñez F, Pérez-López R, Martínez-Díaz JJ, Paredes C, Giner-Robles J, Caselli A, Ibáñez J (2005) Costa Recta Beach, Deception Island, West Antarctica: a retreated scarp of a submarine fault. Antartic Science 17:418-426

García-Yeguas A, Almendros J, Abella R, Ibáñez J (2010) Quantitative analysis of seismic wave propagation anomalies in azimuth and apparent slowness at Deception Island volcano (Antarctica) using seismic arrays. Geophysical Journal International pp doi: 10.1111/j.1365-246X.2010.04,864.x

Haberland C, Rietbrock A (2001) Attenuation tomography in the western central Andes: A detailed insight into the structure of a magmatic arc. Journal of Geophysical Research 106(B6):11,151-11,167

Hansen S, Thurber CH, Mandernach M, Haslinger F, Doran C (2004) Seismic Velocity and Attenuation Structure of the East Rift Zone and South Flank of Kilauea Volcano, Hawaii. Bulletin of the Seismological Society of America 94:1430-1440

Hunsen S, Smith RB, Waite GP (2004) Evidence for gas and magmatic sources beneath Yellowstone volcanic field from seismic tomographic imaging. Journal of Volcanology and Geothermal Research 131:397-410

Ibáñez J, Almendros J, Alguacil G, Morales J, Del Pezzo E, Ortiz R (1997) Eventos ssmicos de largo periodo en la isla decepcin: evidencias de una zona volcnica activa. Boletn de la RSEHN 93:103-110

Ibáñez J, Del Pezzo E, Morales J, Alguacil G, Almendros J, Ortiz R, La Rocca M, García A (2000) Seismovolcanic signals at Deception Island Volcano, Antarctica: wave field analysis and source modelling. Journal of Geophysical Research 135:13,905-13,931

Ibáñez J, Carmona E, Almendros J, Saccorotti G, Del Pezzo E, Abril M, Ortiz R (2003) The 1998-1999 seismic series at deception island volcano, antarctica. Journal of Volcanology and Geothermal Research 128:65-88

Julian BR, Ross A, Foulger GR, Evans JR (1996) Three-dimensional seismic image of a geothermal reservoir: the Geysers, California. Geophysical Research Letters 23:685-688

Julian BR, Pitt A, Foulger GR (1998) Seismic image of CO2 reservoir beneath a seismically active volcano. Geophysical Journal International 133:F7-F10

Koulakov I, Bindi D, Parolai S, Grosser H, Milkereit C (2010) Distribution of Seismic Velocities and Attenuation in the Crust Beneath the North Anatolian Fault (Turkey) from Local Earthquake Tomography. Bulletin of the Seismological Society of America 100(1):207-224

Kusakabe M, Nagao K, Ohba T, Hun Seo J, Park S, Lee J, Park B (2009) Noble gas and stable isotope geochemistry of the thermal fluids from Deception Island, Antarctica. Antarctic Science 21:255-267

Kuznetsov P, Koulakov I (2014) The three-dimensional structure beneath the Popocatépetl volcano (Mexico) based on local earthquake seismic tomography. Journal of Volcanology and Geothermal Research 276:10-21

La Rocca M, Del Pezzo E, Simini M, Scarpa R, De Luca G (2001) Array analysis of seismograms for explosive sources: evidence for surface waves scattered at the main topographical features. Bulletin of the Seismological Society of America 91:219-231

Lees JM, Lindley GT (1994) Three-dimensional Attenuation Tomography at Loma Prieta: Inverting t* for Q. Journal of Geophysical Research 99(B4):6843-6863 
Luzón F, Almendros J, García-Jerez A (2011) Shallow structure of Deception Island, Antarctica, from correlations of ambient noise on a set of dense seismic arrays. Geophysical Journal International 185:737-748

Maestro A, Somoza L, Rey J, Martnez-Fras J, Lpez-Martnez J (2007) Active tectonics, fault patterns and stress field of deception island: a response to oblique convergence between the pacific and antartic plates. Journal of South American Earth Sciences 23:256-268

Martí J, Vila J, Rey J (1996) Deception island (bransfield strait, antarctica): an example of a volcanic caldera development by extensional tectonics. McGuire, W J, Jones, A P and Neuberg, J, eds Volcano instability on the Earth and other planets Special Publication of the Geological Society, London 110:253-265

Martí J, Geyer A, Aguirre-Díaz G (2013) Origin and evolution of the Deception Island caldera (South Shetland Islands, Antarctica). Bulletin of Volcanology 75:732-750

Muñoz Martín A, Catalan M, Martin J, Carbo A (2005) Upper structure of Deception Island area (Bransfield Strait, Antarctica) from gravity and magnetic modelling. Antarctic Science 17:213-224

Martinez-Arevalo C, Bianco F, Ibáñez J, Del Pezzo E (2003) Shallow seismic attenuation and shear-wave splitting in the short-period range of Deception Island volcano (Antarctica). Journal of Volcanology and Geothermal Research 128:89-113

Matsumoto S, Uehira K, Watanabe A, Goto K, Iio Y, Hirata N, Okada T, Takahashi H, Shimizu H, Shinohara M, Kanazawa T (2009) High resolution $Q^{-1}$ estimation based on extension of coda normalization method and its application to $\mathrm{P}$-wave attenuation structure in the aftershock area of the 2005 West Off Fukuoka Prefecture Earthquake (M 7.0). Geophysical Journal International 179:1039-1054

Melo R, Vieira G, Caselli A, Ramos M (2012) Susceptibility modelling of hummocky terrain distribution using the information value method (Deception Island, Antarctic Peninsula). Geomorphology 155-156:88-95

Morozov IB (2011) Mechanisms of geometrical seismic attenuation. Annals of Geophysics $54(3)$

Muksin U, Haberland C, Bauer K, Weber M (2013) Three-dimensional upper crustal structure of the geothermal system in Tarutung (North Sumatra, Indonesia) revealed by seismic attenuation tomography. Geophysical Journal International 195, doi: 10.1093/gji/ggt383:2037-2049

Ortiz R, García A, Aparicio A, Blanco I, Felpeto A, Del Rey R, Villegas MT, Ibáñez J, Morales J, Del Pezzo E, Olmedillas J, Astiz MM, Vila J, Ramos M, Viramonte JG, Risso C, Caselli A (1997) Monitoring of the volcanic activity of deception island, south shetland islands, antarctica (1986-1995). In: Ricci, CA (Ed) The Antarctic Region: Geological Evolution and Processes, Terra Antartica Publications, Siena pp pp. 1071-1076

Pedrera A, Ruíz-Constán A, Heredia N, Galindo-Zaldívar J, Bohoyo F, Marín-Lechado C, Ruano P, Somoza L (2012) The fracture system and the melt emplacement beneath the Deception Island active volcano, South Shetland Islands, Antarctica. Antarctic Science 24:173-182

Prates G, Berrocoso M, Fernndez-Ros A, Garca A (2013) Enhancement of sub-daily positioning solutions for surface deformation monitoring at deception volcano (south shetland islands, antarctica). Bulletin of Volcanology 75:1-10

Priyono A, Suantika G, Widiyantoro S, Nugraba AD (2011) Three-dimensioanl seismic attenuation structure of Mt. Guntur, West Java, Indonesia. International Journal of Tomography and Simulation 17:17-28

Prudencio J, Ibáñez J, García-Yeguas A, Del Pezzo E (2013) Spatial distribution of intrinsic and scattering seismic attenuation in active volcanic islands, II: Deception island images. Geophysical Journal International 195 (3):1957-1969, doi: 10.1093/gji/ggt360

Saccorotti G, Almendros J, Carmona E, Ibáñez J, Del Pezzo E (2001) Slowness Anomalies from two dense seismic arrays at Deception Island volcano, Antarctica. Bulletin of Seismological Society of America 91:561-571

Sato H, Fehler MC, Maeda T (2012) Seismic Wave Propagation and Scattering in the heterogeneous Earth: Second Edition. Springer, New York, USA

Schurr B, Asch G, Rietbrock A, Trumbull R, Haberland CH (2003) Complex patterns of fluid and melt transport in the central Andean subduction zone revealed by attenuation tomography. Earth and Planetary Science Letters 215:105-119 
Smellie JL (2001) Lithostraigraphy and volcanic evolution of deception island, south shetland islands. Antartic Science 13:118-209

Smellie JL, López-Martínez J, Headland RK, Hernández-Cifuentes F, Maestro A, Millar IL, Thomson JW (2002) Geology and geomorphology of Deception Island. Cambridge, British Antarctic Survey, p 77p

Takanami T, Selwyn Sacks I, Hasegawa A (2000) Attenuation structure beneath the volcanic front in northeastern Japan from broad-band seismograms. Physics of the Earth and Planetary Interior 121:339-357

Tejedo P, Gutirrez B, Pertierra LR, Benayas J (2014) Analysis of published scientific research from deception island, south shetland islands. Antarctic Science p doi:10.1017/S0954102014000455

Torrecillas C, Berrocoso M, Pérez-López R, Torrecillas M (2012) Determination of volumetric variations and coastal changes due to historical volcanic eruptions using historical maps and remote-sensing at Deception Island (West-Antarctica). Geomorphology 136:614

Torrecillas C, Berrocoso M, Felpeto A, Torrecillas M, García A (2013) Reconstructing palaeo-volcanic geometries using a Geodynamic Regression Model (GRM): Application to Deception Island Volcano (South Shetland Islands, Antarctica). Geomorphology 182:79-88

Vanorio T, Virieux J, Capuano P, Russo G (2005) Three-dimensional tomography from $\mathrm{P}$ wave and $\mathrm{S}$ wave microearthquake travel times and rock physics characterization of the Campi Flegrei Caldera. Journal of Geophysical Research 110(B03201):doi:10.129/2004JB003,102

Vila J, Martí J, Ortiz R, García A, Correig AM (1992) Volcanic tremors at deception island, south shetland islands, antarctica. Journal of Volcanology and Geothermal Research $53: 1-4$

Vila J, Correig AM, Martí J (1995) Attenuation source parameters at Deception Island (South Shetland Islands, Antarctica). Pure and Applied Geophysics 144:229-250

Yoshimoto K, Sato H, Ohtake M (1993) Frequency-dependent attenuation of P and S waves in Kanto area, Japan, based on the coda-normalization method. Geophysical Journal International 114:165-174

Zandomeneghi D, Barclay A, Almendros J, Ibáñez J, Wilcock WSD (2009) Crustal structure of Deception Island volcano from P-wave seismic tomography: tectonic and volcanic implications. Journal of Geophysical Research 114 

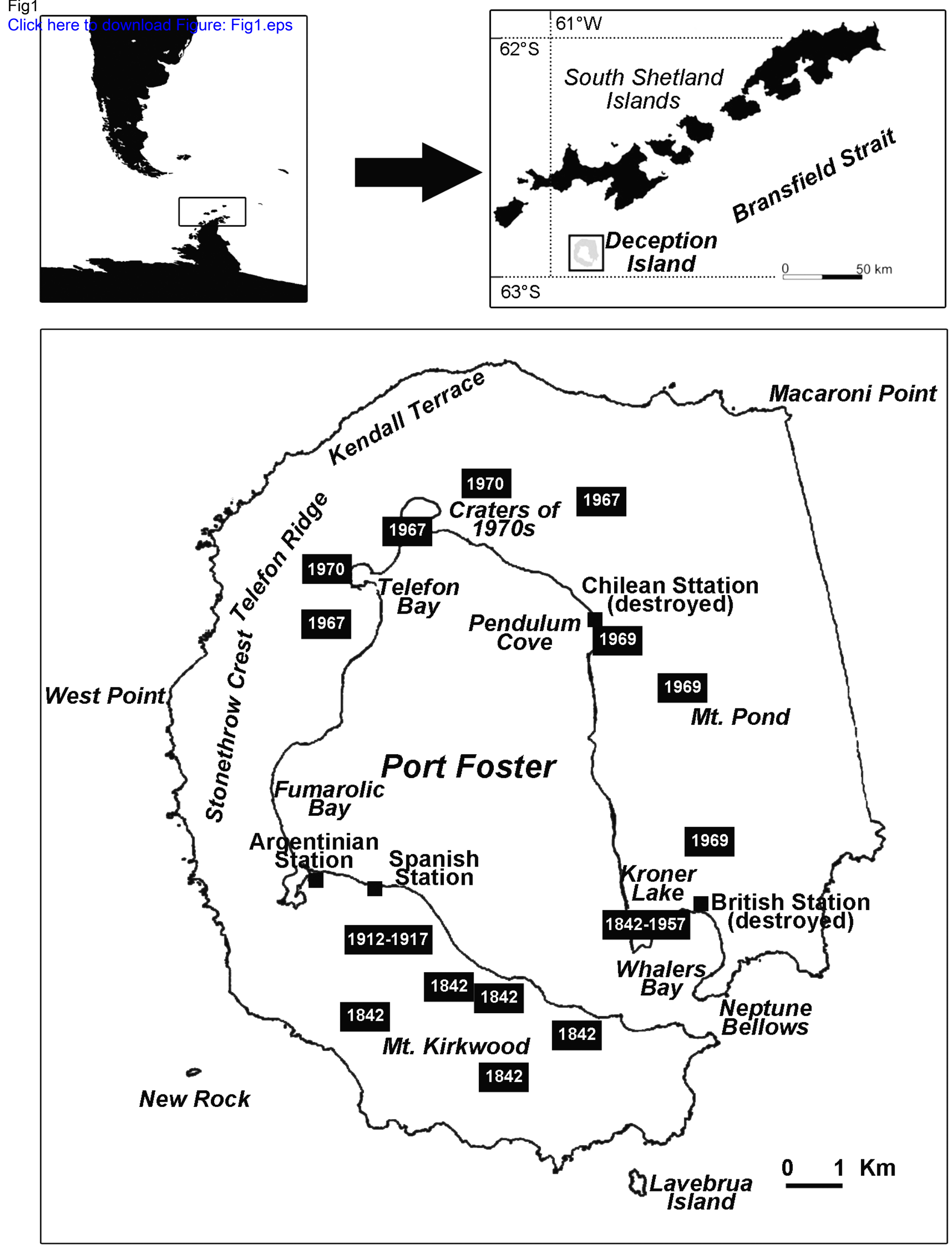

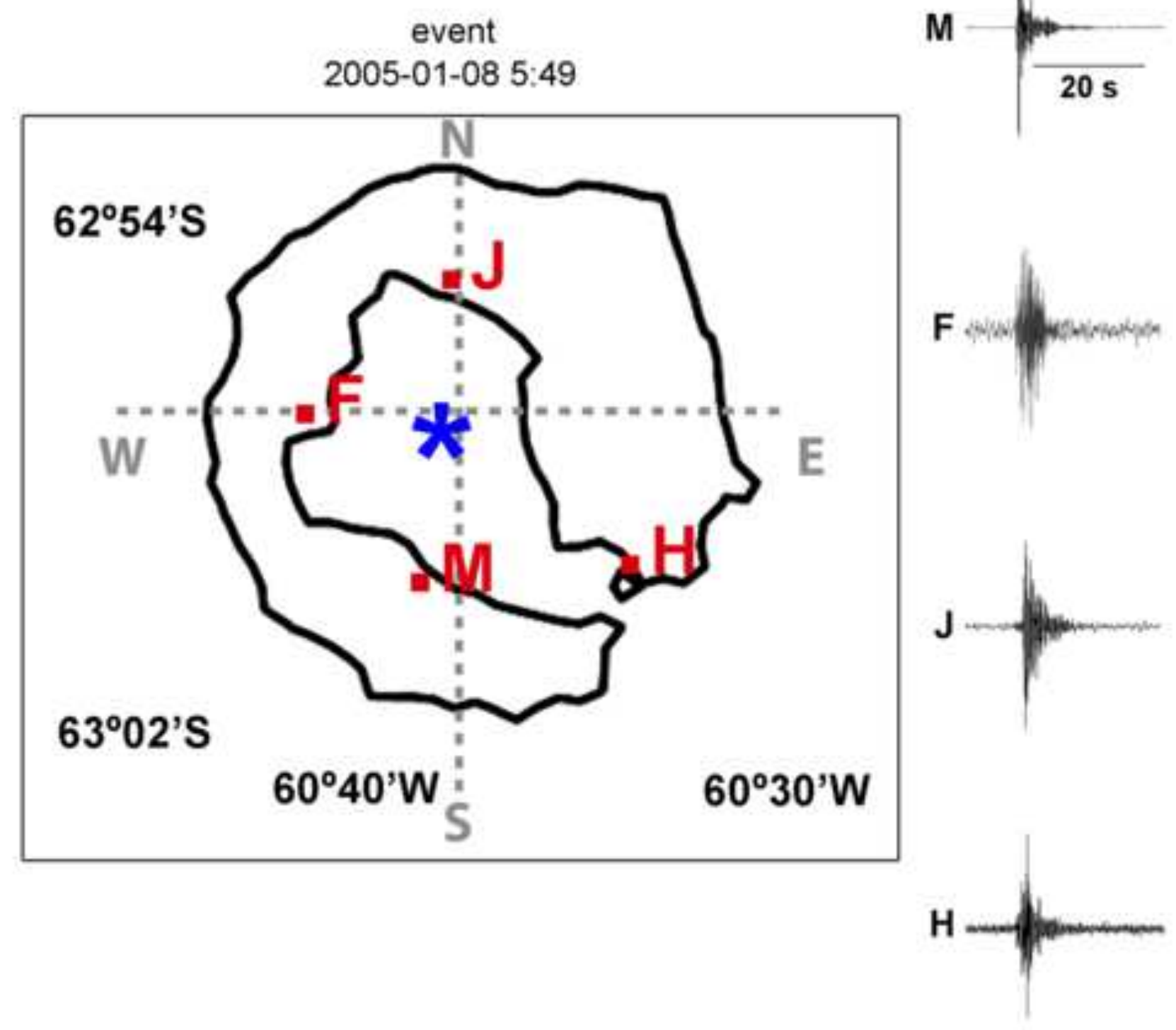

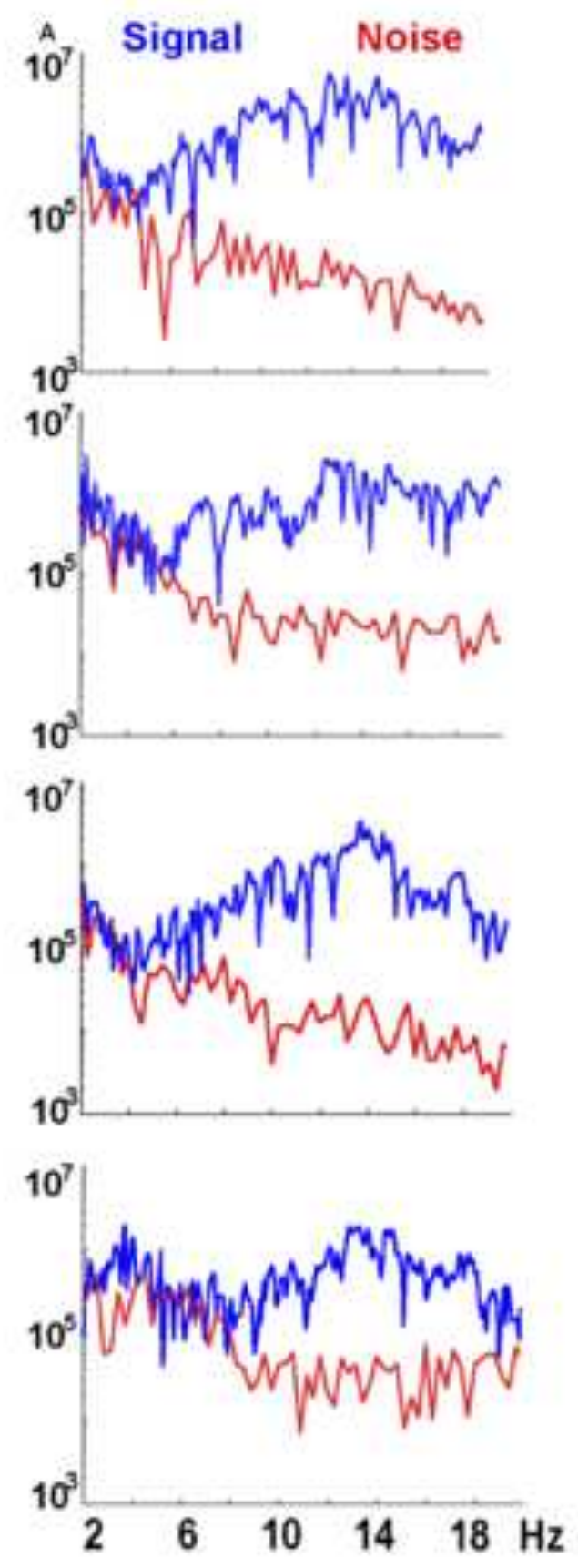


Fig3

Click here to download high resolution image

a)
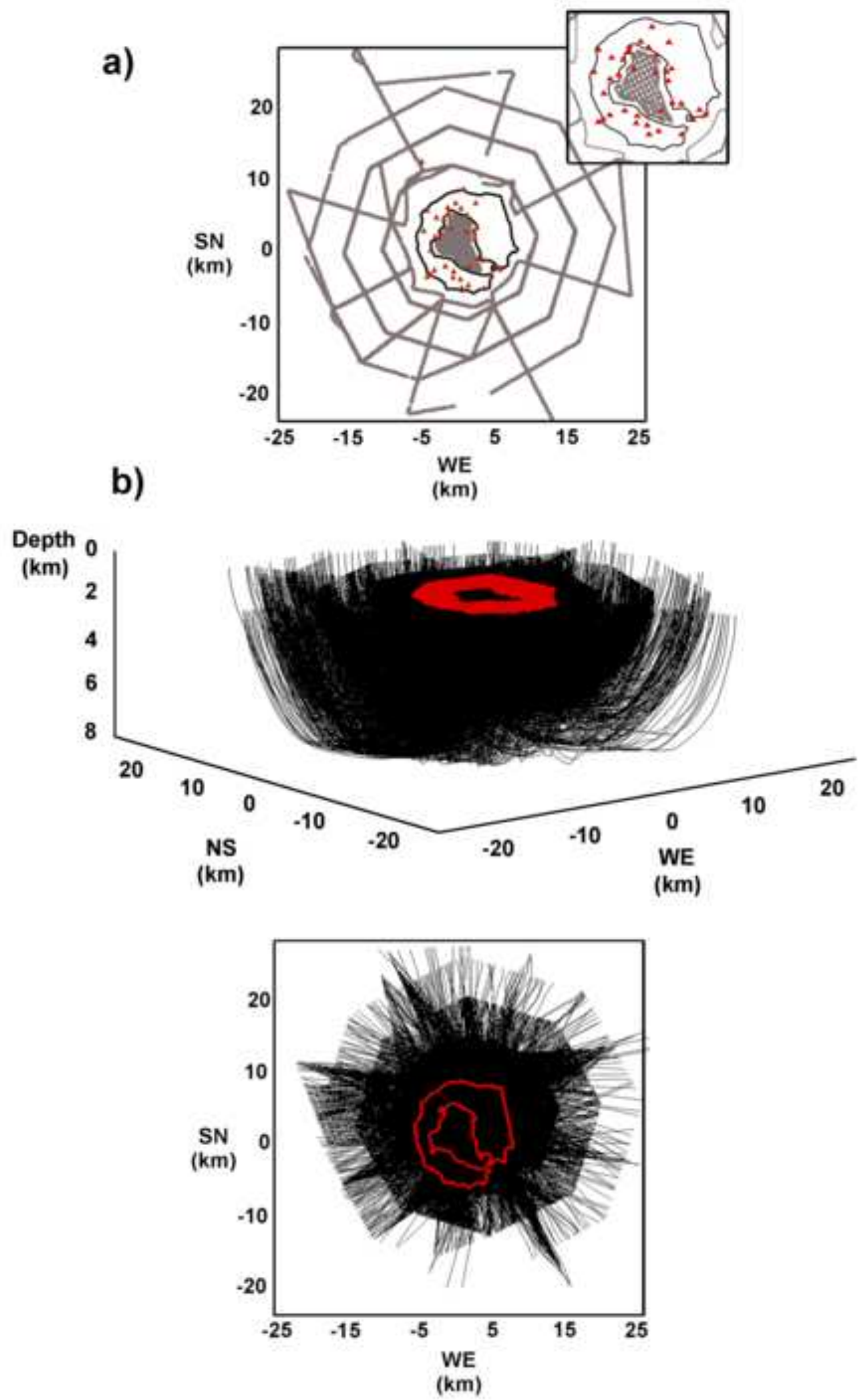

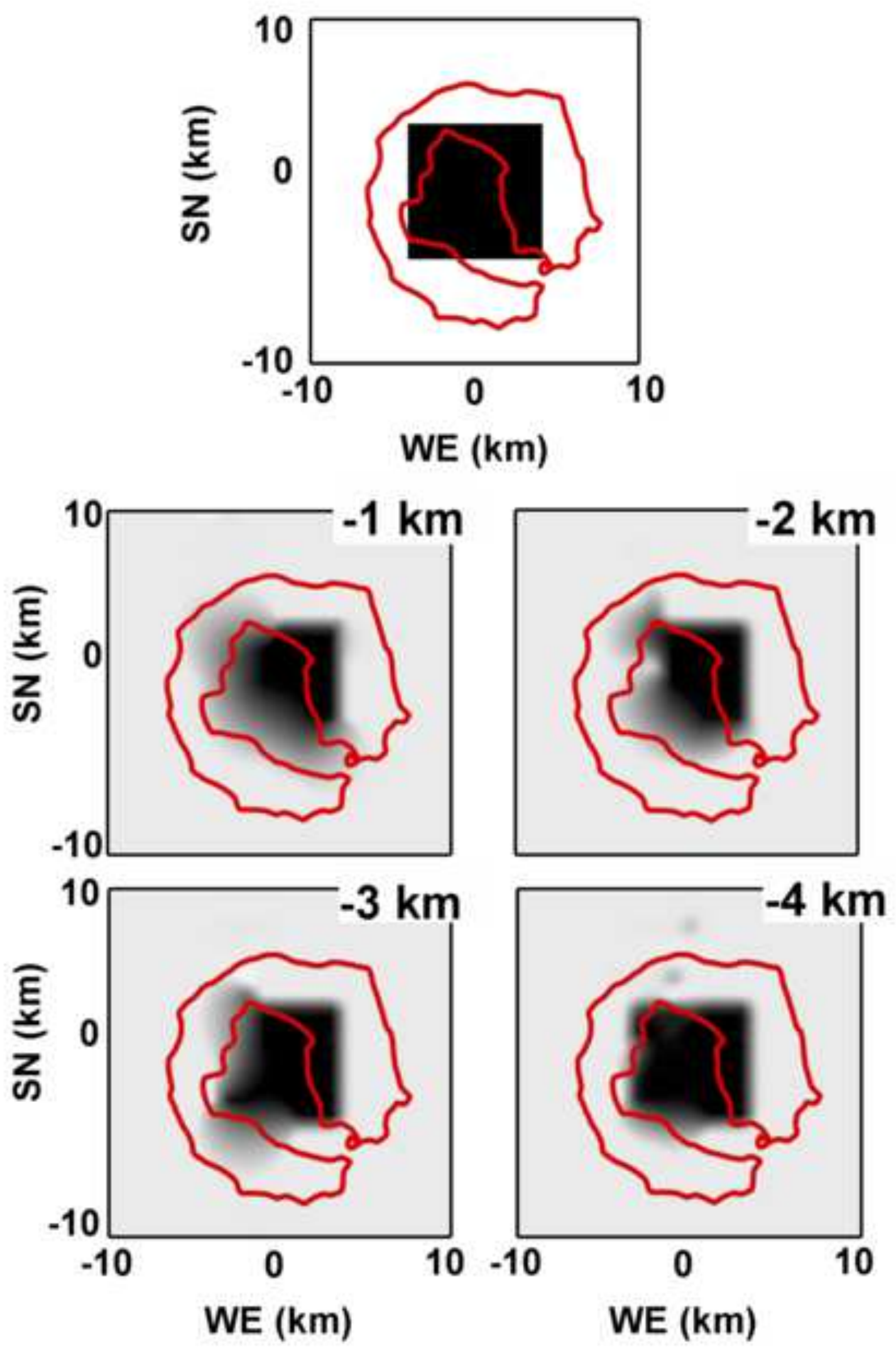

$\Delta \mathrm{Qp}^{-1}$

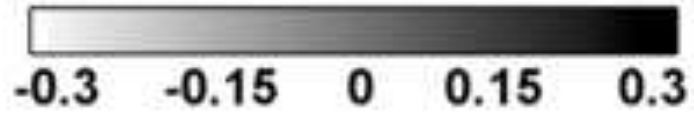



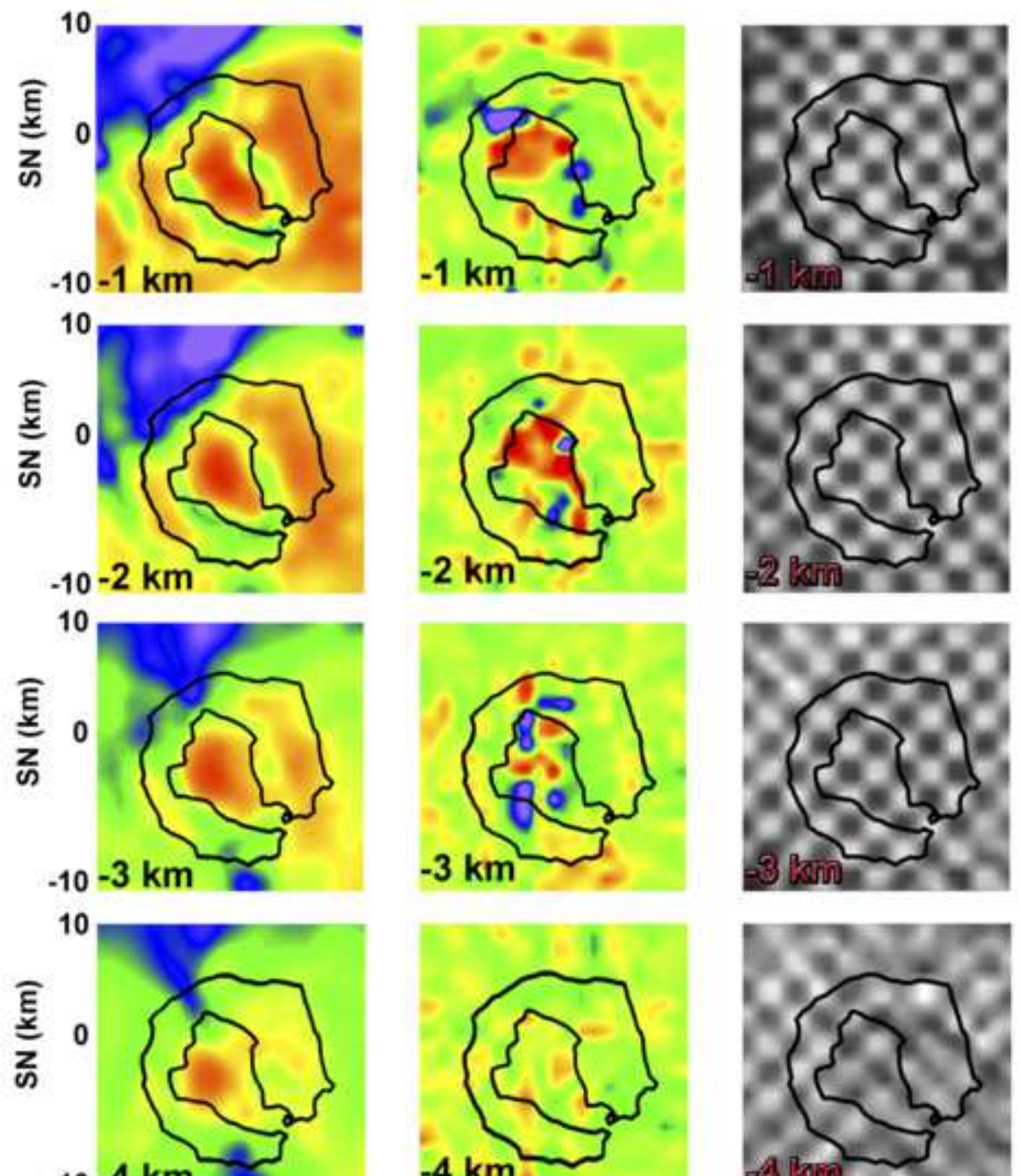

$-10-4 \mathrm{~km}$
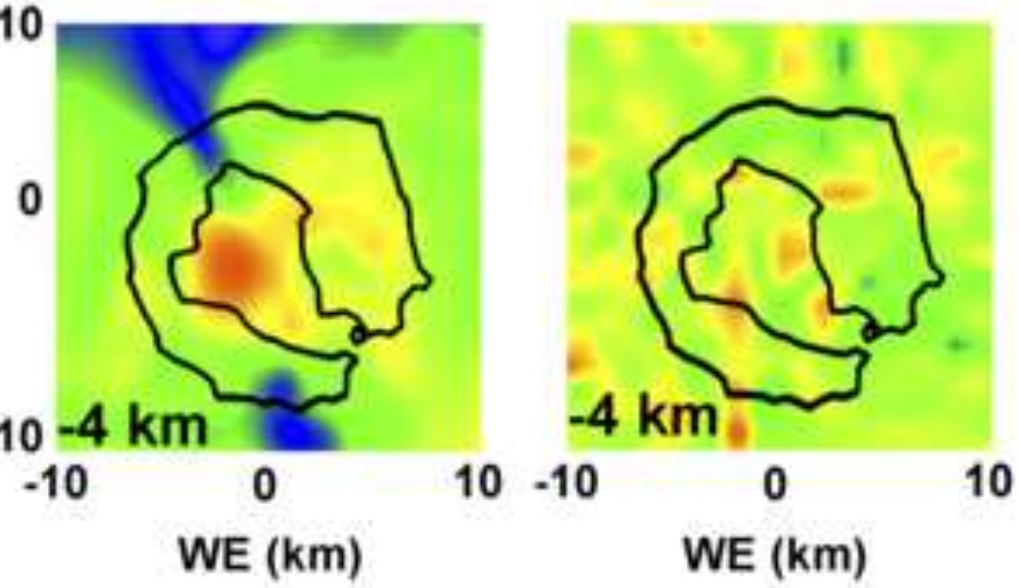

WE (km)
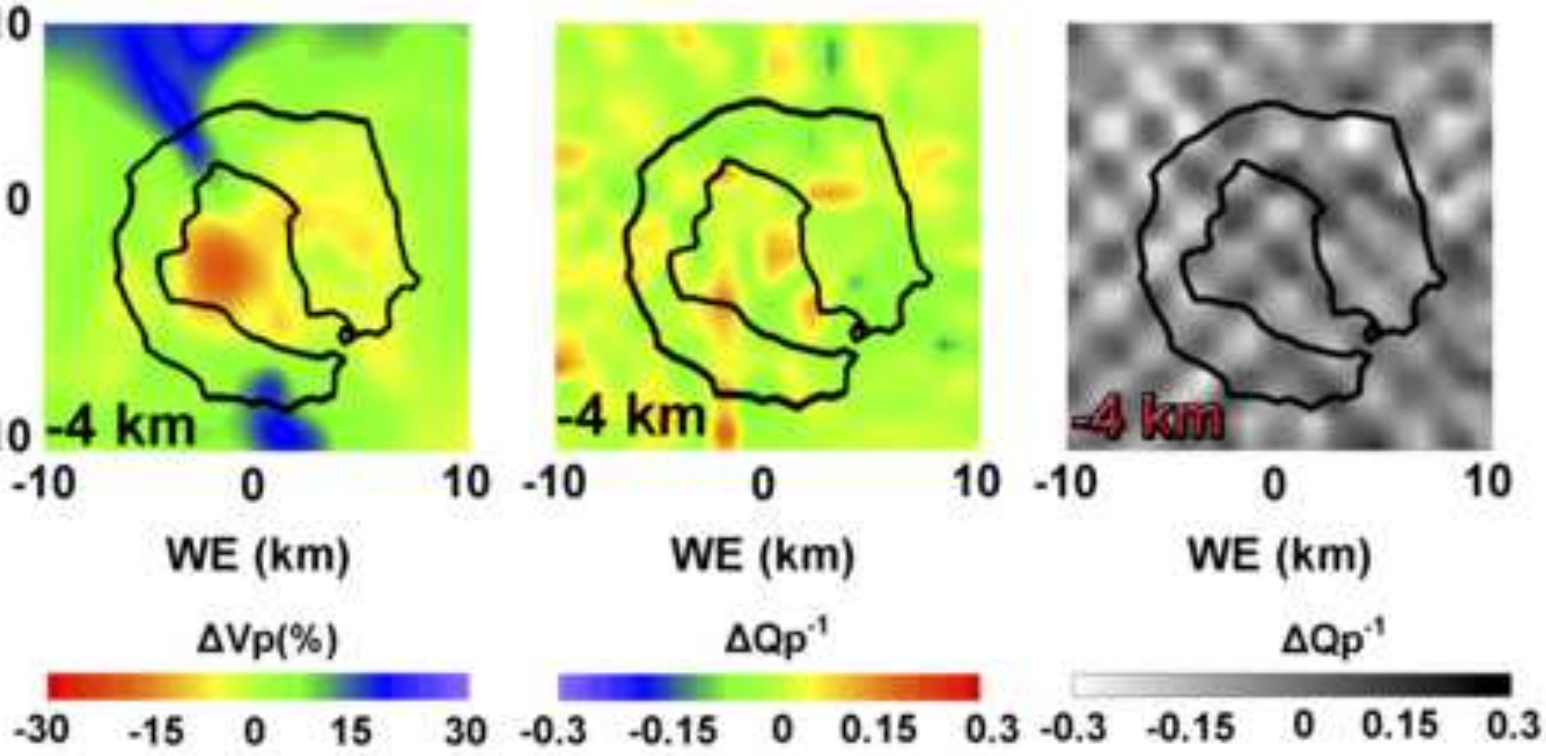


\section{Fig6}

Click here to download high resolution image

a)
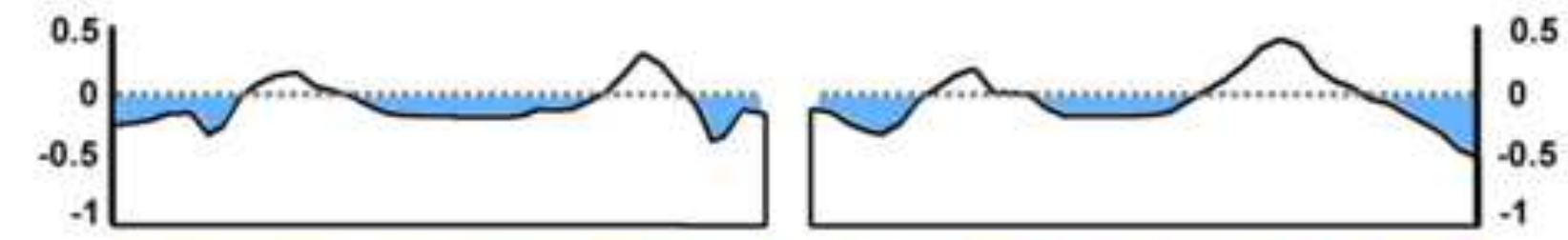

b)
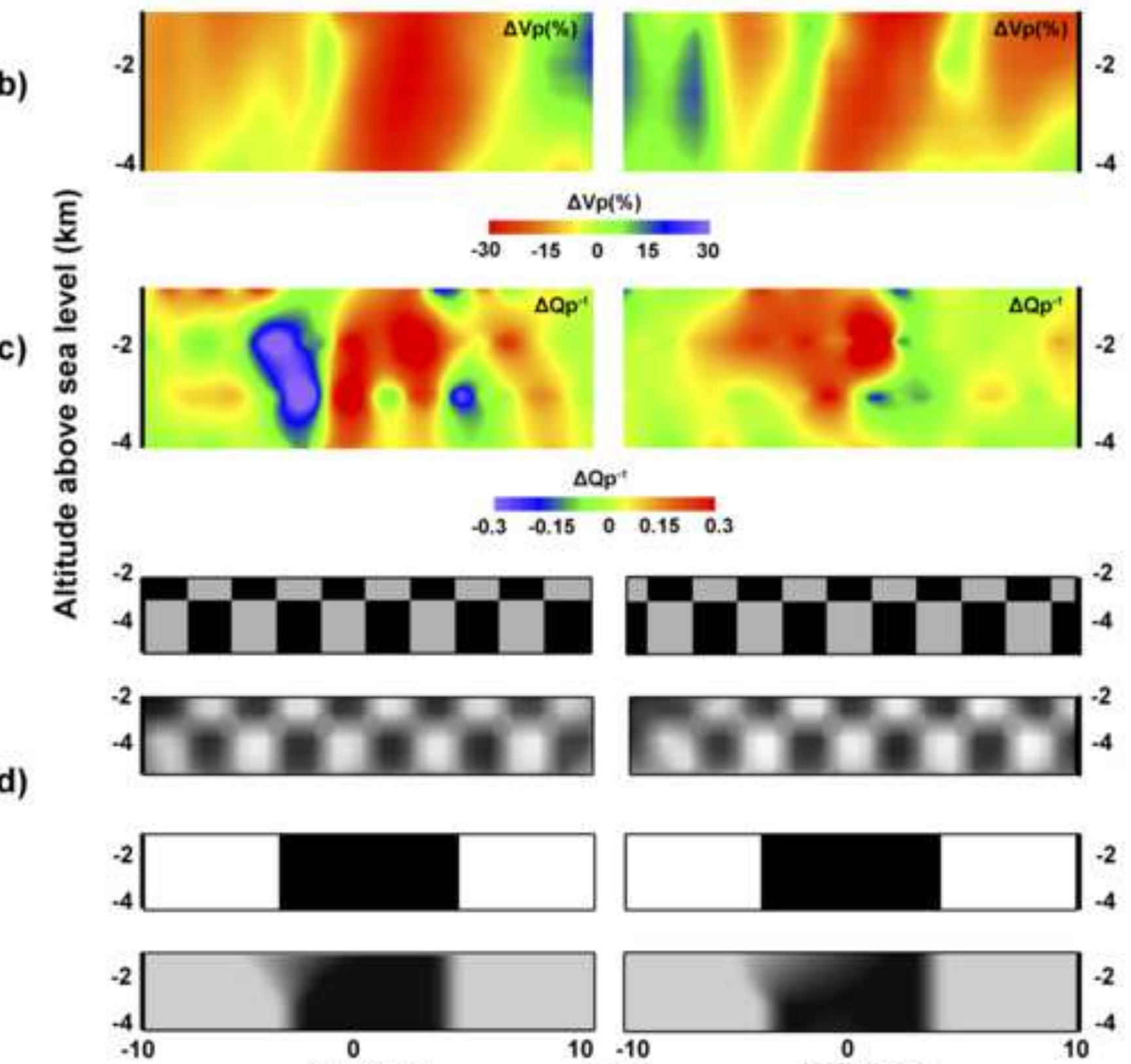

$\mathrm{SN}(\mathrm{km})$

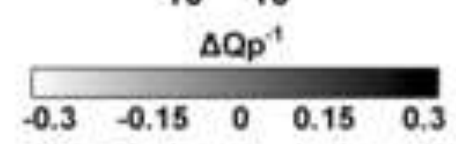

WE (km) 
MODEL A: Geothermal effect

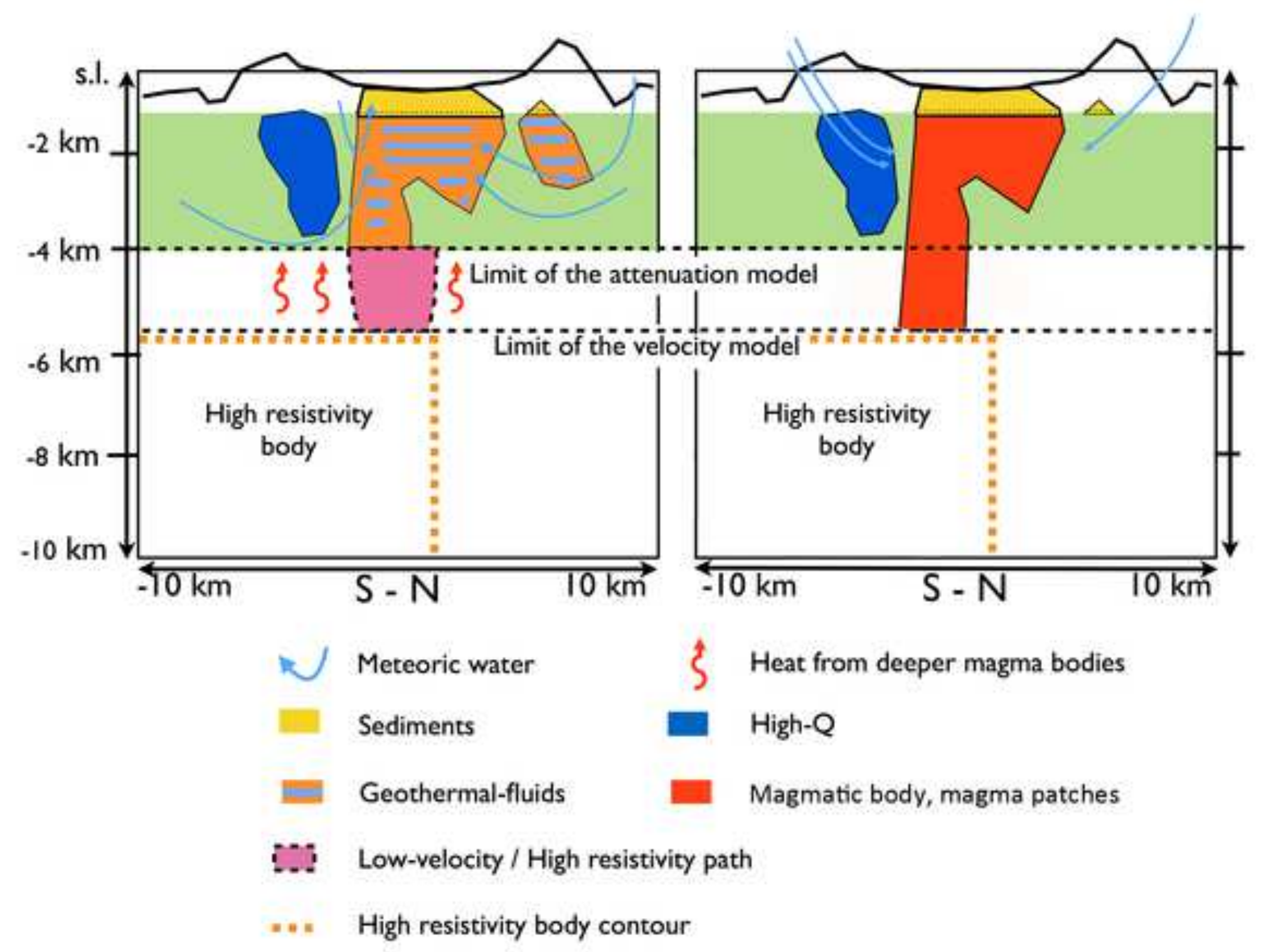

MODEL B: Shallow melted material

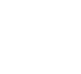

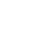

